\title{
Transcriptomic Analysis of Listeria monocytogenes in Response to Bile Under Aerobic and Anaerobic Conditions
}

\author{
Damayanti Chakravarty ${ }^{1}$, Gyan Sahukhal', Mark Arick II ${ }^{2}$, Morgan L. Davis ${ }^{3}$ and \\ Janet $R$. Donaldson ${ }^{1 *}$ \\ ${ }^{1}$ Cell and Molecular Biology, The University of Southern Mississippi, Hattiesburg, MS, United States, ${ }^{2}$ Institute \\ for Genomics, Biocomputing \& Biotechnology, Mississippi State University, Mississippi State, MS, United States, \\ ${ }^{3}$ Department of Biological Sciences, Mississippi State University, Mississippi State, MS, United States
}

Listeria monocytogenes is a gram-positive facultative anaerobic bacterium that causes the foodborne illness listeriosis. The pathogenesis of this bacterium depends on its survival in anaerobic, acidic, and bile conditions encountered throughout the gastrointestinal (Gl) tract. This transcriptomics study was conducted to analyze the differences in transcript levels produced under conditions mimicking the Gl tract. Changes in transcript levels were analyzed using RNA isolated from L. monocytogenes strain F2365 at both aerobic and anaerobic conditions, upon exposure to 0 and $1 \%$ bile at acidic and neutral $\mathrm{pH}$. Transcripts corresponding to genes responsible for pathogenesis, cell wall associated proteins, DNA repair, transcription factors, and stress responses had variations in levels under the conditions tested. Upon exposure to anaerobiosis in acidic conditions, there were variations in the transcript levels for the virulence factors internalins, listeriolysin $\mathrm{O}$, etc., as well as many histidine sensory kinases. These data indicate that the response to anaerobiosis differentially influences the transcription of several genes related to the survival of $L$. monocytogenes under acidic and bile conditions. Though further research is needed to decipher the role of oxygen in pathogenesis of $L$. monocytogenes, these data provide comprehensive information on how this pathogen responds to the Gl tract.

Keywords: Listeria monocytogenes, transcriptomics, anaerobiosis, bile, stress response, anaerobic

\section{INTRODUCTION}

Listeria monocytogenes is a gram-positive foodborne pathogen that is responsible for the disease listeriosis (Scallan et al., 2011). Pregnant women, infants, elderly, and immunocompromised individuals are more susceptible to listeriosis, with meningitis, septicemia, and spontaneous abortions being possible manifestations of the disease (Thigpen et al., 2011). Being a foodborne pathogen, this bacterium must be able to respond to the stressors encountered following ingestion of contaminated food. Low $\mathrm{pH}$, bile, and hypoxic/anoxic environments are some of the key stressors that are encountered by L. monocytogenes within the gastrointestinal (GI) tract (Davis et al., 1996). 
Low $\mathrm{pH}$ of the stomach is one of the initial stressors encountered by L. monocytogenes upon ingestion (White et al., 2015). The low $\mathrm{pH}$ of the gastric secretion is a roadblock to invasion by the bacteria. Listeria's acid response involves the SOS response, LisRK (a two-component regulatory system that regulates listerial osmotolerance), components of sigma $B$ regulon, ATPase proton pump, and enzymatic systems that regulate internal hydrogen ion concentration (Sleator and Hill, 2005). A transcriptomic study that was performed on Listeria grown in the presence of organic acids revealed an increase in the transcript levels of sigma B and prfA regulated genes, which included internalins, phospholipases, and other virulence genes. This previous study also indicated an up-regulation of oxidative stress defenses, DNA repair, intermediary metabolism, cell wall modification, and cofactor and fatty acid biosynthesis (Tessema et al., 2012). A proteomic study performed on Listeria grown in the presence of organic salts demonstrated an up-regulation of oxidoreductases and lipoproteins. Upon exposure to hydrochloric acid, it was also observed that proteins involved in respiration (enzyme dehydrogenases and reductases), osmolyte transport, protein folding and repair, general stress resistance, flagella synthesis and metabolism were expressed in the response to the acidic conditions (Bowman et al., 2012).

Listeria is also exposed to bile within the GI tract (White et al., 2015). Bile is synthesized by the liver and stored in the gall bladder. It is released into the duodenum during digestion (Monte et al., 2009). The bile acids are the antibacterial component of bile; bile acids induce damage to the cell wall and DNA (Coleman et al., 1979; Bernstein et al., 1999; Prieto et al., 2004, 2006). Within the gall bladder, bile is found at a nearly neutral $\mathrm{pH}$ (7.5), while in the duodenum it is more acidic ( $\mathrm{pH}$ 5.5) (White et al., 2015). Bile is more bactericidal at acidic $\mathrm{pH}$ than at a neutral $\mathrm{pH}$, as indicated in a study that showed a decrease in survival in bile under $\mathrm{pH} 5.5$ in comparison to a $\mathrm{pH}$ of 7.5 (Dowd et al., 2011). Many studies have been conducted to determine the global response of L. monocytogenes to bile encountered within the GI tract. For instance, the transcription factor $b r t A$, which senses cholic acid and regulates efflux pumps (MdrM and MdrT) is involved in bile tolerance (Quillin et al., 2011). Bile salt hydrolases neutralize conjugated bile acids, thereby providing protection against the bactericidal properties of bile (Dowd et al., 2011). The bilE gene is also involved in detoxifying bile acids (Dowd et al., 2011).

In addition to changes in $\mathrm{pH}$ and bile, L. monocytogenes is also exposed to changes in oxygen concentrations. The duodenum is considered microaerophilic in nature, while the gall bladder is anaerobic (Zheng et al., 2015). Oxygen availability has been found to influence bile resistance. A proteomics study performed under anaerobic conditions in the presence of bile observed notable alterations in cell wall associated proteins, DNA repair proteins and oxidative stress response proteins. Under anaerobic conditions the Listeria adhesion protein has been observed to have a significant role in intestinal infection (Burkholder et al., 2009). Additionally, oxygen deprivation has been found to affect the survival of L. monocytogenes in vitro (Payne et al., 2013;
Wright et al., 2016), as well as in cell cultures, guinea pigs (Bo Andersen et al., 2007), and gerbils (Harris et al., 2019). These studies highlight the importance of oxygen in regulation of virulence. However, it is not known what the transcriptomic response of L. monocytogenes is to conditions that mimic the GI tract under physiologically relevant anaerobic conditions. Therefore, the goal of this study was to determine the impact of oxygen on the transcriptomic response of L. monocytogenes to bile in conditions that mimic the duodenum ( $\mathrm{pH}$ 5.5) and the gall bladder ( $\mathrm{pH} 7.5)$.

\section{RESULTS}

\section{Survival of $L$. monocytogenes in Conditions Mimicking Gastrointestinal Tract}

Listeria monocytogenes exhibits slightly slower growth rates under anaerobic conditions (Figures 1A vs. 1B). Bile also impacted the viability of $L$. monocytogenes strain F2365 differently under anaerobic conditions. Under neutral $\mathrm{pH}$, bile did not have a significant impact on survival of L. monocytogenes strain F2365 under either aerobic (Figure 1A) or anaerobic conditions (Figure 1B).

At acidic $\mathrm{pH}$ in the presence of bile, which mimics the exposure to bile in the duodenum, the percentage of L. monocytogenes that survived significantly declined (Figure 2A; $p<0.05)$. This further demonstrates the increase in toxicity exhibited by bile when in acidic conditions. Survival also declined under anaerobic conditions in comparison to time $0 \mathrm{~h}$ (Figure 2B, $p<0.05$ ). However, the decrease in viability was not as severe under anaerobic conditions (Figure 2B) in comparison to aerobic conditions (Figure 2A; $p<0.05$ ). This indicates that anaerobic conditions improve the survival of $L$. monocytogenes to the toxic effects of bile.

\section{Overall Changes in Transcript Levels in Response to Conditions Mimicking the Gastrointestinal Tract}

As significant alterations in survival were observed following $1 \mathrm{~h}$ of bile exposure under acidic conditions, this time point was selected to compare the impact that oxygen had on the transcriptome. Table 1 shows the overall changes in transcripts detected. Under anaerobic conditions, a total of 190 transcripts in media at $\mathrm{pH} 7.5$ and 268 at $\mathrm{pH}$ of 5.5 were identified to be differentially expressed in comparison to aerobic conditions. In the presence of bile and absence of oxygen, 304 and 434 transcripts were differentially produced at $\mathrm{pH} 7.5$ and 5.5, respectively. Under anaerobic conditions, upon exposure to bile, variations in the transcript levels of 200 genes were identified at $\mathrm{pH} 7.5$ and 419 at $\mathrm{pH}$ 5.5. For all conditions tested, there were globally more transcripts identified to be up-regulated than down-regulated, except for acidic bile conditions under anaerobic growth. 
A

F2365 Aerobic pH 7.5

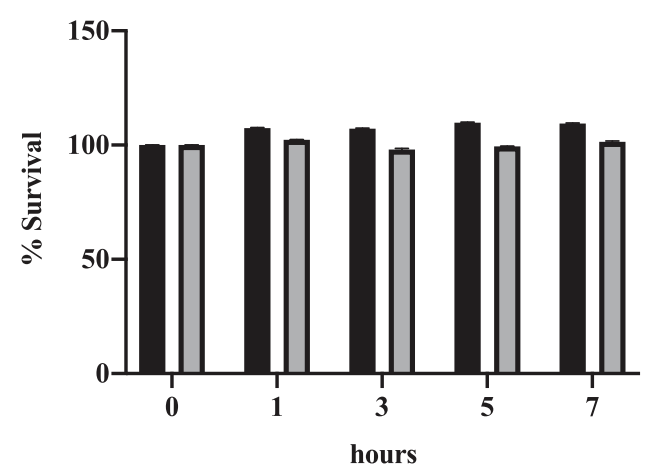

B

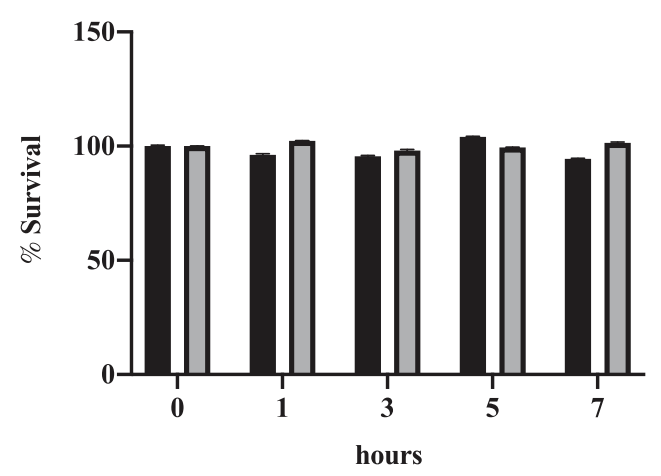

FIGURE 1 | Impact of oxygen on the survival of $L$. monocytogenes in conditions mimicking the gall bladder. F2365 was exposed to either aerobic (A) or anaerobic (B) conditions with $0 \%$ bile (black bars) or $1 \%$ bile (gray bars) at a pH of 7.5 and survival was measured by viable plate counts over $7 \mathrm{~h}$.

Data represent averages of three independent replicates. Error bars represent standard deviation from biological replicates.

\section{Changes in Transcript Levels in Response to Anaerobic Conditions}

Transcripts representative of five genes were found to be increased in expression levels under exposure to anaerobic conditions regardless of whether the cultivation was conducted under either neutral or acidic pH (Table 2 and Supplementary Figure 1). These included genes involved in membrane transport, protein folding, and stress response. Of these transcripts the amino acid transporter (LMOf2365_2333) had nearly a 9-fold increase in levels at neutral $\mathrm{pH}$ in comparison to acidic $\mathrm{pH}$. Transcripts representative of the dnaJ (LMOf2365_1491) and dnaK (LMOf2365_1492) genes, which encode for molecular chaperones and have roles in phagocytosis and protein homeostasis, were also increased under anaerobic conditions at both $\mathrm{pH}$ conditions tested. The transcript representative of the cadA (LMOf2365_0672) gene, which encodes for a heavy metal translocating P-type ATPase and is a component of the CadAC efflux cassette, was also increased 6.1-fold at pH 7.5 and 3.8 at $\mathrm{pH}$ 5.5 under oxygen depleted conditions (Table 2 ).

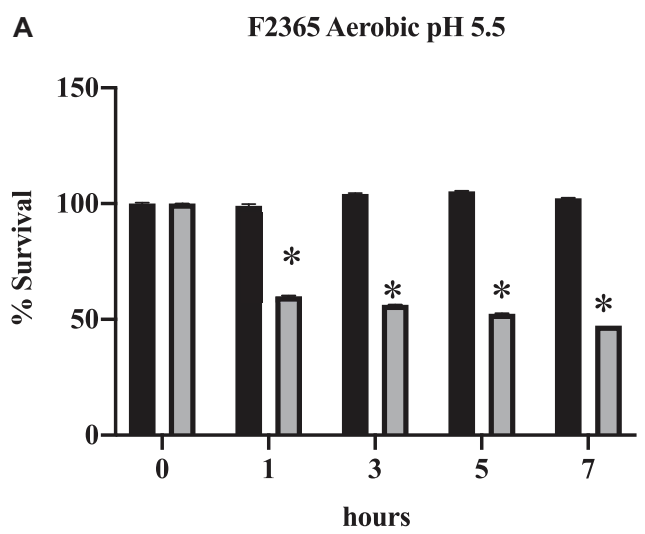

B

F2365 Anaerobic pH 5.5

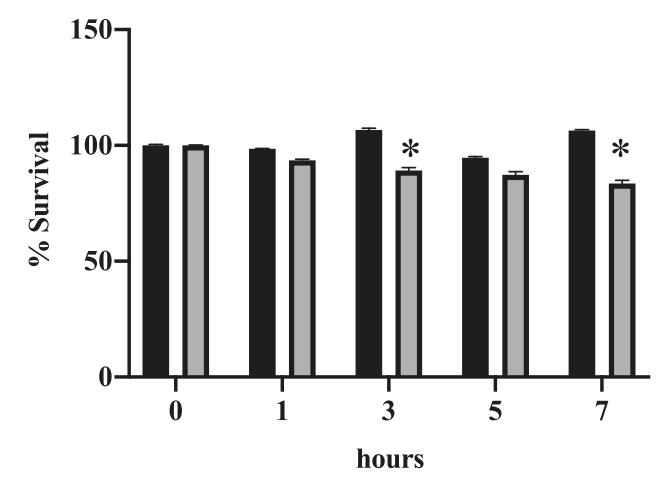

FIGURE 2 | Impact of oxygen on the survival of $L$. monocytogenes in conditions mimicking the duodenum. F2365 was exposed to either aerobic (A) or anaerobic conditions (B) with $0 \%$ bile (black bars) or $1 \%$ bile (gray bars) at a $\mathrm{pH}$ of 5.5 and survival was measured by viable plate counts over $7 \mathrm{~h}$. Data represent averages of three independent replicates. Error bars represent standard deviation from biological replicates. * Indicates $p<0.05$ in comparison to time 0 .

The transcript levels of 18 genes were decreased under anaerobic conditions regardless of the $\mathrm{pH}$ condition tested (Table 3 and Supplementary Figure 2). Out of these eighteen transcripts, six were representative of uncharacterized hypothetical proteins; all of these had lower transcript levels under neutral conditions in comparison to acidic conditions. This could suggest that these hypothetical genes are regulated similarly. The remaining transcripts identified encoded for stress response, membrane associated protein, and metabolism protein (Table 3).

\section{Changes in Transcript Levels in Response to Anaerobic Acidic Conditions}

In acidic conditions, transcript levels of 140 genes were increased (Table 4 and Supplementary Figure 1) and 104 were decreased under anaerobiosis (Table 5). Analyzing these transcripts upregulated in response to acidic conditions under anaerobiosis 
TABLE 1 | Total changes in transcript levels following exposure to bile at pH of 7.5 or 5.5 under either aerobic or anaerobic conditions.

\begin{tabular}{|c|c|c|c|}
\hline & Aerobic vs. Anaerobic & Bile Aerobic vs. Bile Anaerobic & Anaerobic vs. Bile Anaerobic \\
\hline \multirow[t]{2}{*}{$\mathrm{pH} 7.5$} & Total = 190 & Total = 304 & Total = 200 \\
\hline & $U p=125$ Down $=65$ & $U p=207$ Down = 97 & $U p=131$ Down = 69 \\
\hline \multirow[t]{2}{*}{$\mathrm{pH} 5.5$} & Total $=268$ & Total $=434$ & Total $=419$ \\
\hline & $U p=147$ Down $=121$ & $U p=213$ Down $=221$ & $U p=264$ Down = 155 \\
\hline
\end{tabular}

TABLE 2 | Transcript levels increased in response to anaerobiosis at pH 7.5 or 5.5.

\begin{tabular}{lccc}
\hline Gene ID & Gene product & \multicolumn{2}{c}{ Transcript fold changes } \\
\cline { 2 - 4 } & Membrane transport & $\mathbf{p H ~ 7 . 5}$ & $\mathbf{p H ~ 5 . 5}$ \\
\hline cadA LMOf2365_0672 & $\begin{array}{c}\text { Cadmium translocating } \\
\text { P-type ATPase }\end{array}$ & 6.1 & 3.8 \\
LMOf2365_2333 & Amino acid antiporter & 137.2 & 15.0 \\
Protein folding & Chaperone protein & 5.3 & 8.6 \\
$\begin{array}{l}\text { dnaK LMOf2365_1492 } \\
\text { dnaJ LMOf2365_1491 }\end{array}$ & Chaperone protein & 7.2 & 4.8 \\
Stress response & Glutamate & 11.2 & 3.2 \\
gadG LMOf2365_2405 & decarboxylase gamma & & \\
\hline
\end{tabular}

revealed that several biological pathways related to pathogenesis, stress response, membrane associated proteins, transcription factors and DNA repair mechanisms influenced the survival of L. monocytogenes (Table 4). Transcripts representative of genes involved in metabolism, transcription factor and pathogenesis were down-regulated (Table 5). Certain transcripts encoding for glycolytic enzymes increased under acidic anaerobic conditions as well (Table 4). These included the glyceraldehyde-3-phosphate dehydrogenase (5.4-fold increase), phosphoglycerate mutase (4.7-fold increase), and pyruvate kinase (6.7-fold increase).

\section{Changes in Transcript Levels in Response to Bile Under Anaerobic Conditions}

Transcripts representative of 53 genes were found to be upregulated in response to exposure to bile under anaerobic conditions (Table 6 and Supplementary Figure 3). Transcripts encoding for transcription regulators of virulence, antibiotic resistance, metabolism, and membrane associated proteins were also observed to increase in their levels of expression (Table 6). Transcripts representative of nine genes were down-regulated under anaerobic conditions in presence of bile at both $\mathrm{pH} 7.5$ and 5.5 (Table 7 and Supplementary Figure 4). Fold changes of the transcript levels of genes associated with metabolism, translation, pathogenesis, and transcription were down-regulated (Table 7).

\section{Changes in Transcript Levels in Response to Bile Under Acidic and Anaerobic Conditions}

Transcript levels of 210 genes were up-regulated in response to bile at acidic pH under anaerobic conditions (Table 8 and Supplementary Figure 3). Transcripts encoding for transcription
TABLE 3 | Transcript levels decreased in response to anaerobiosis at $\mathrm{pH} 7.5$ or 5.5 .

\begin{tabular}{|c|c|c|c|}
\hline \multirow[t]{2}{*}{ Gene ID } & \multirow[t]{2}{*}{ Gene product } & \multicolumn{2}{|c|}{ Transcript fold changes } \\
\hline & & pH 7.5 & pH 5.5 \\
\hline \multicolumn{4}{|l|}{ Membrane transport } \\
\hline LMOf2365_2554 & Sensor histidine kinase & -4.46 & -12.1 \\
\hline \multicolumn{4}{|l|}{ Metabolism } \\
\hline $\begin{array}{l}\text { acpP LMOf2365_1834 } \\
\text { LMOf2365_0511 }\end{array}$ & $\begin{array}{l}\text { Acyl carrier protein } \\
\text { Heme oxygenase } \\
\text { (staphylobilin- } \\
\text { producing) }\end{array}$ & -13.6 & -5.3 \\
\hline gcvT LMOf2365_1365 & $\begin{array}{l}\text { Glycine cleavage } \\
\text { system T protein }\end{array}$ & -8.9 & -4.7 \\
\hline LMOf2365_0585 & $\begin{array}{l}\text { Phosphoglycerate } \\
\text { mutase family protein }\end{array}$ & -7.7 & -3.6 \\
\hline \multicolumn{4}{|l|}{ Stress response } \\
\hline LMOf2365_0544 & $\begin{array}{l}\text { Universal stress protein } \\
\text { family }\end{array}$ & -5.9 & -5.8 \\
\hline \multicolumn{4}{|l|}{ Hypothetical proteins } \\
\hline LMOf2365_0964 & $\begin{array}{c}\text { Conserved hypothetical } \\
\text { protein }\end{array}$ & -13.7 & -5.9 \\
\hline LMOf2365_0511 & $\begin{array}{c}\text { Conserved hypothetical } \\
\text { protein }\end{array}$ & -13.6 & -5.3 \\
\hline LMOf2365_1087 & $\begin{array}{c}\text { Conserved hypothetical } \\
\text { protein }\end{array}$ & -12.1 & -3.9 \\
\hline LMOf2365_0808 & $\begin{array}{c}\text { Conserved hypothetical } \\
\text { protein }\end{array}$ & -11.2 & -3.1 \\
\hline LMOf2365_1179 & Hypothetical protein & -8.3 & -3.7 \\
\hline LMOf2365_2288 & $\begin{array}{c}\text { Conserved hypothetical } \\
\text { protein }\end{array}$ & -6.3 & -5.8 \\
\hline
\end{tabular}

factors, metabolism, replication and repair, cell signaling, protein folding, and pathogenesis were also found to be up-regulated. Additionally, transcripts representing 146 genes were downregulated under anaerobic conditions with acidic bile (Table 9 and Supplementary Figure 4), with these being primarily associated with metabolism, membrane transport, replication and repair, pathogenesis, and transcription factors.

\section{DISCUSSION}

\section{Anaerobiosis Improves Survival of L. monocytogenes in Conditions Mimicking the Gastrointestinal Tract}

Survival of L. monocytogenes strain F2365 was analyzed under conditions mimicking the GI tract. This strain was chosen as it 
TABLE 4 | Transcript levels increased for select genes in response to anaerobiosis at $\mathrm{pH} 5.5$.

Gene ID Gene product $\begin{gathered}\text { Transcript } \\ \text { fold changes }\end{gathered}$

\section{Metabolism}

hemL LMOf2365_1574

nrdD LMOf2365_029

panD LMOf2365_1929

LMOf2365_0434

pepQ LMOf2365_1600

Idh-2 LMOf2365_1553

LMOf2365_2670

LMOf2365_1275

LMOf2365_0372

LMOf2365_2200

LMOf2365_0846

LMOf2365_0277

asnB LMOf2365_1687

pfl-1 LMOf2365_1425

LMOf2365_2673

LMOf2365_0330

mvaS LMOf2365_1434

LMOf2365_1633

LMOf2365_1642

LMOf2365_0603

LMOf2365_0550

pnp LMOf2365_134

Gpm LMOf2365_2238

LMOf2365_1226

LMOf2365_2528

gap LMOf2365_2432

LMOf2365_1083

LMOf2365_2199

LMOf2365 1400

LMOf2365_1299

Pyk LMOf2365_1592

Idh-1 LMOf2365_0221

pflA LMOf2365_1426

galU LMOf2365_1099

LMOf2365_0582

LMOf2365_2144
Glutamate-1-semialdehyde-2,1aminomutase

Anaerobic

ribonucleoside-triphosphate

reductase

Phosphate

acetyl/butyryltransferase family

protein

Aspartate 1-decarboxylase

Polysaccharide deacetylase

family protein

Proline dipeptidase

L-lactate dehydrogenase

$\mathrm{N}$-acetylmuramoyl-L-alanine

amidase, family 4

Hydrolase, alpha/beta fold family

Transcriptional regulator, DeoR

family

Putative lactoylglutathione lyase

Pyruvate flavodoxin/ferredoxin

oxidoreductase

Glycosyl hydrolase, family 1

Asparagine synthase

(glutamine-hydrolyzing)

Formate acetyltransferase

Orn/Lys/Arg decarboxylase

Threonine aldolase family protein

Hydroxymethylglutaryl-CoA

synthase

Putative glutamyl-aminopeptidase

Dipeptidase

Glycosyl hydrolase, family 1

Glycosyl hydrolase, family 4

Polyribonucleotide

nucleotidyltransferase

Phosphoglycerate mutase

Putative peptidase

Putative fructose-bisphosphate

aldolase

Glyceraldehyde-3-phosphate

dehydrogenase, type I

Inositol monophosphatase family

protein

Metallo-beta-lactamase family

protein

Putative acylphosphatase

4-hydroxybenzoyl-CoA

thioesterase family protein

Pyruvate kinase

L-lactate dehydrogenase

Pyruvate formate-lyase activating enzyme

UTP-glucose-1-phosphate

uridylyltransferase

CBS domain protein

Nitroreductase family

protein
TABLE 4 | (Continued)

\begin{tabular}{|c|c|c|}
\hline Gene ID & Gene product & $\begin{array}{l}\text { Transcript } \\
\text { fold changes }\end{array}$ \\
\hline LMOf2365_0802 & $\begin{array}{l}\text { Putative acyl-carrier protein } \\
\text { phosphodiesterase }\end{array}$ & 9.4 \\
\hline ald LMOf2365_1601 & Alanine dehydrogenase & 11.9 \\
\hline manA LMOf2365_2143 & $\begin{array}{l}\text { Mannose-6-phosphate } \\
\text { isomerase, class I }\end{array}$ & 13.6 \\
\hline LMOf2365_1608 & $\begin{array}{l}\text { Putative inorganic } \\
\text { polyphosphate/ATP-NAD kinase }\end{array}$ & 13.6 \\
\hline LMOf2365_2308 & Aminopeptidase C & 13.9 \\
\hline pfl-2 LMOf2365_1946 & Formate acetyltransferase & 40.3 \\
\hline murl LMOf2365_1246 & Glutamate racemase & 68 \\
\hline \multicolumn{3}{|l|}{ Transcription factors } \\
\hline LMOf2365_2140 & $\begin{array}{l}\text { Transcriptional regulator, DeoR } \\
\text { family }\end{array}$ & 3.1 \\
\hline $\operatorname{argR}$ LMOf2365_1384 & Arginine repressor & 3.2 \\
\hline LMOf2365_1526 & DNA-binding response regulator & 4.1 \\
\hline LMOf2365_1907 & $\begin{array}{l}\text { Iron-dependent repressor family } \\
\text { protein }\end{array}$ & 4.3 \\
\hline LMOf2365_0755 & $\begin{array}{l}\text { Transcriptional regulator, PadR } \\
\text { family }\end{array}$ & 4.6 \\
\hline LMOf2365_0480 & Putative transcriptional regulator & 4.8 \\
\hline LMOf2365_1986 & $\begin{array}{l}\text { Transcriptional regulator, Fur } \\
\text { family }\end{array}$ & 4.8 \\
\hline LMOf2365_0814 & $\begin{array}{l}\text { Transcriptional regulator, MarR } \\
\text { family }\end{array}$ & 7.8 \\
\hline LMOf2365_1707 & $\begin{array}{l}\text { Peroxide operon transcriptional } \\
\text { regulator }\end{array}$ & 8.6 \\
\hline \multicolumn{3}{|l|}{ Pathogenesis } \\
\hline LMOf2365_1812 & Internalin family protein & 5.4 \\
\hline hly LMOf2365_0213 & Listeriolysin $\mathrm{O}$ & 10.2 \\
\hline \multicolumn{3}{|l|}{ Motility } \\
\hline LMOf2365_1723 & $\begin{array}{l}\text { Methyl-accepting chemotaxis } \\
\text { protein }\end{array}$ & 4.4 \\
\hline \multicolumn{3}{|l|}{ DNA repair } \\
\hline topA LMOf2365_1293 & DNA topoisomerase I & 3.3 \\
\hline nth LMOf2365_1923 & Endonuclease III & 3.5 \\
\hline exoA LMOf2365_1807 & Exodeoxyribonuclease & 4.2 \\
\hline LMOf2365_1643 & MutT/nudix family protein & 4.4 \\
\hline ung-2 LMOf2365_1236 & Uracil-DNA glycosylase & 5.3 \\
\hline \multicolumn{3}{|l|}{ Stress response } \\
\hline LMOf2365_1997 & $\begin{array}{l}\text { Putative tellurite resistance } \\
\text { protein }\end{array}$ & 3.1 \\
\hline LMOf2365_0783 & Glyoxalase family protein & 3.4 \\
\hline LMOf2365_0963 & Peroxide resistance protein Dpr & 3.5 \\
\hline LMOf2365_2735 & General stress protein 26 & 5.1 \\
\hline LMOf2365_1121 & Glyoxalase family protein & 5.2 \\
\hline \multicolumn{3}{|l|}{ Protein folding } \\
\hline groEL LMOf2365_2099 & Chaperone protein GroEL & 4.0 \\
\hline atpB LMOf2365_2508 & ATP synthase FO, A subunit & 4.1 \\
\hline
\end{tabular}

is a serotype $4 \mathrm{~b}$ strain, which represents the serotype of a large portion of outbreak strains. F2365 was isolated from one of the deadliest outbreaks of L. monocytogenes (Linnan et al., 1988). F2365 has been sequenced (Nelson et al., 2004) and has been extensively studied for genomic analyses (Chatterjee et al., 2006; Liu and Ream, 2008; Payne et al., 2013), making it an ideal strain to analyze transcriptomic responses. 
TABLE 5 | Transcript levels decreased for select genes in response to anaerobiosis at $\mathrm{pH} 5.5$.

\begin{tabular}{|c|c|c|}
\hline Gene ID & Gene product & $\begin{array}{l}\text { Transcript } \\
\text { fold changes }\end{array}$ \\
\hline \multicolumn{3}{|l|}{ Metabolism } \\
\hline pheA LMOf2365_1555 & Prephenate dehydratase & -18.8 \\
\hline LMOf2365_2263 & Putative arsenate reductase & -14.8 \\
\hline LMOf2365_1556 & $\begin{array}{l}\text { GTP-binding protein, GTP1/OBG } \\
\text { family }\end{array}$ & -13.4 \\
\hline LMOf2365_0148 & $\begin{array}{l}\text { Ser/Thr protein phosphatase family } \\
\text { protein }\end{array}$ & -13.2 \\
\hline LMOf2365_2831 & Sucrose phosphorylase & -9.3 \\
\hline LMOf2365_0128 & Lipase & -8.9 \\
\hline cah LMOf2365_0827 & Carbonic anhydrase & -8.9 \\
\hline LMOf2365_2647 & $\begin{array}{l}\text { Galactitol PTS system EllA } \\
\text { component }\end{array}$ & -8.5 \\
\hline tkt-3 LMOf2365_2640 & Transketolase & -6.2 \\
\hline $\operatorname{arcA}$ LMOf2365_0052 & Arginine deiminase & -6.1 \\
\hline LMOf2365_2643 & $\begin{array}{l}\text { Alcohol dehydrogenase, } \\
\text { zinc-dependent }\end{array}$ & -5.7 \\
\hline qoxA LMOf2365_0016 & $\begin{array}{l}\text { Cytochrome aa3-600 menaquinol } \\
\text { oxidase subunit II, Oxidative } \\
\text { phosphorylation }\end{array}$ & -5.5 \\
\hline gabD LMOf2365_0935 & $\begin{array}{l}\text { Succinate-semialdehyde } \\
\text { dehydrogenase }\end{array}$ & -5.4 \\
\hline LMOf2365_2364 & $\begin{array}{l}\text { Ferredoxin/flavodoxin-NADP+ } \\
\text { reductase }\end{array}$ & -5.3 \\
\hline LMOf2365_0209 & $\begin{array}{l}\text { UDP-N-acetylglucosamine } \\
\text { pyrophosphorylase }\end{array}$ & -4.9 \\
\hline guaB LMOf2365_2746 & $\begin{array}{l}\text { Inosine-5'-monophosphate } \\
\text { dehydrogenase }\end{array}$ & -4.3 \\
\hline LMOf2365_0566 & $\begin{array}{l}\text { Putative N-carbamoyl-L-amino acid } \\
\text { amidohydrolase }\end{array}$ & -4.1 \\
\hline ctaB LMOf2365_2088 & Heme o synthase & -4.1 \\
\hline prs-1 LMOf2365_0210 & $\begin{array}{l}\text { Ribose-phosphate } \\
\text { pyrophosphokinase }\end{array}$ & -3.9 \\
\hline LMOf2365_1048 & $\begin{array}{l}\text { Metallo-beta-lactamase family } \\
\text { protein }\end{array}$ & -3.6 \\
\hline LMOf2365_2576 & $\begin{array}{l}\text { Acetamidase/formamidase family } \\
\text { protein }\end{array}$ & -3.4 \\
\hline LMOf2365_2824 & Glycosyl transferase, family 65 & -3.0 \\
\hline \multicolumn{3}{|l|}{ Transcription Factors } \\
\hline ada, LMOf2365_0093 & $\begin{array}{l}\text { AraC family transcriptional } \\
\text { regulator }\end{array}$ & -9.4 \\
\hline LMOf2365_0127 & $\begin{array}{l}\text { Transcriptional regulator, AraC } \\
\text { family }\end{array}$ & -7.2 \\
\hline purr LMOf2365_0203 & Pur operon transcriptional repressor & -4.3 \\
\hline LMOf2365_1683 & $\begin{array}{l}\text { Phosphosugar-binding } \\
\text { transcriptional regulator, RpiR family }\end{array}$ & -4.2 \\
\hline LMOf2365_0023 & $\begin{array}{l}\text { Transcriptional regulator, GntR } \\
\text { family }\end{array}$ & -4.0 \\
\hline LMOf2365_2467 & $\begin{array}{l}\text { Phosphate transport system } \\
\text { protein PhoU }\end{array}$ & -4.0 \\
\hline LMOf2365_2017 & Lacl family transcriptional regulator & -3.3 \\
\hline LMOf2365_2224 & $\begin{array}{l}\text { ArsC family protein, regulatory } \\
\text { protein spx }\end{array}$ & -3.3 \\
\hline LMOf2365_1010 & $\begin{array}{l}\text { Transcriptional regulator, MarR } \\
\text { family }\end{array}$ & -3.1 \\
\hline Membrane Transport & & \\
\hline
\end{tabular}

(Continued)
TABLE 5 | (Continued)

\begin{tabular}{|c|c|c|}
\hline Gene ID & Gene product & $\begin{array}{c}\text { Transcript } \\
\text { fold changes }\end{array}$ \\
\hline LMOf2365_1428 & $\begin{array}{l}\text { MFS transporter, ACDE family, } \\
\text { multidrug resistance protein }\end{array}$ & -7.9 \\
\hline LMOf2365_2542 & $\begin{array}{l}\text { Peptide/nickel transport system } \\
\text { substrate-binding protein; bacterial } \\
\text { extracellular solute-binding protein, } \\
\text { family } 5\end{array}$ & -7.7 \\
\hline LMOf2365_2575 & $\begin{array}{l}\text { Putative Mg2+ transporter-C } \\
\text { (MgtC) family protein }\end{array}$ & -5.4 \\
\hline LMOf2365_0759 & $\begin{array}{l}\text { Methyl-accepting chemotaxis } \\
\text { protein }\end{array}$ & -4.2 \\
\hline LMOf2365_0267 & $\begin{array}{l}\text { Sugar ABC transporter, } \\
\text { sugar-binding protein }\end{array}$ & -4.0 \\
\hline LMOf2365_0167 & $\begin{array}{l}\text { Peptide/nickel transport system } \\
\text { substrate-binding protein }\end{array}$ & -3.9 \\
\hline LMOf2365_2351 & $\begin{array}{l}\text { Multicomponent } \mathrm{Na}+\mathrm{H}+ \\
\text { antiporter subunit } \mathrm{A}\end{array}$ & -3.3 \\
\hline LMOf2365_0876 & $\begin{array}{l}\text { Sugar ABC transporter, } \\
\text { sugar-binding protein }\end{array}$ & -3.1 \\
\hline LMOf2365_2732 & $\begin{array}{l}\text { ATP-binding cassette, subfamily } B \text {, } \\
\text { bacterial AbcA/BmrA }\end{array}$ & -3.1 \\
\hline \multicolumn{3}{|l|}{ Pathogenesis } \\
\hline LMOf2365_0128 & Lipase & -8.9 \\
\hline inlE LMOf2365_0283 & Internalin E & -6.7 \\
\hline LMOf2365_2467 & $\begin{array}{l}\text { Phosphate transport system } \\
\text { protein PhoU }\end{array}$ & -4.0 \\
\hline
\end{tabular}

Bile is made in the liver, stored in the gall bladder, and released to the duodenum upon ingestion. The environment in the gall bladder is anaerobic and neutral $\mathrm{pH}$, while the duodenum is acidic and microaerophilic (Zheng et al., 2015). The alterations in oxygen availability within the GI tract are essential to developing the redox relationship between microbes and host (He et al., 1999; Espey, 2013). Therefore, we tested how oxygen influenced the survival of L. monocytogenes under either acidic (mimicking the duodenum) or neutral (mimicking the gall bladder) bile conditions.

Since variations in transcript levels were observed due to alterations in oxygen availability, we wanted to determine which genes were commonly expressed under anaerobiosis. Transcript levels of five genes were found to be up-regulated under exposure to anaerobic conditions regardless of whether the cultivation was conducted under either neutral or acidic $\mathrm{pH}$ (Table 2), though there were differential expressions between the two conditions. Transcripts common to both conditions included two membrane transporters LMOf2365_2333 and cadA (LMOf2365_0672), two chaperones, and the stress response related gene gadG (LMOf2365_2405). CadA has been previously shown to be involved in formation of biofilms at $25^{\circ} \mathrm{C}$ by L. monocytogenes (Parsons et al., 2017). CadA also has been implicated in having roles in virulence and pathogenesis (Parsons et al., 2017). Therefore, it is possible that CadA is involved in stress response mechanisms related to anaerobic survival and that the formation of biofilms may be a critical component to survival. Previous studies have also shown that various stressors 
TABLE 6 | Transcript levels increased for select genes in response to anaerobiosis at pH of 7.5 and 5.5.

\begin{tabular}{|c|c|c|c|}
\hline \multirow[t]{2}{*}{ Gene ID } & \multirow{2}{*}{$\begin{array}{l}\text { Gene product } \\
\text { Transcription factors }\end{array}$} & \multicolumn{2}{|c|}{ Transcript fold changes } \\
\hline & & pH 7.5 & pH 5.5 \\
\hline LMOf2365_0641 & Transcriptional regulator, MarR family & 6.5 & 13.7 \\
\hline prfA LMOf2365_0211 & Listeriolysin regulatory protein & 11.5 & 3.7 \\
\hline LMOf2365_1986 & Fur family transcriptional regulator, ferric uptake regulator & 12.7 & 18.8 \\
\hline glnR LMOf2365_1316 & Transcriptional repressor GlnR & 13.6 & 13.9 \\
\hline \multicolumn{4}{|l|}{ Metabolism } \\
\hline LMOf2365_2358 & Thioesterase family protein & 4.2 & 6.4 \\
\hline LMOf2365_0884 & ATP-dependent RNA helicase DeaD & 4.4 & 3.1 \\
\hline LMOf2365_1433 & Acetyl-CoA acetyltransferase & 4.5 & 6.6 \\
\hline LMOf2365_1729 & Deoxynucleoside kinase family protein & 4.6 & 10.5 \\
\hline LMOf2365_1660 & Muramoyltetrapeptide carboxypeptidase & 5.1 & 4.4 \\
\hline cysK LMOf2365_0234 & Cysteine synthase A & 6.1 & 6.2 \\
\hline LMOf2365_1038 & Putative PTS system, glucose-specific, IIA component & 6.3 & 4.4 \\
\hline LMOf2365_2371 & NifU family protein & 6.9 & 27.1 \\
\hline Cah LMOf2365_0827 & Carbonic anhydrase & 7.1 & 7.2 \\
\hline LMOf2365_1419 & Acetyltransferase, GNAT family & 7.3 & 3.7 \\
\hline $\operatorname{trxB}$ LMOf2365_2451 & Selenocompound metabolism & 8.7 & 5.0 \\
\hline glnA LMOf2365_1317 & Glutamine synthetase, type I & 9.9 & 3.3 \\
\hline LMOf2365_2364 & Pyridine nucleotide-disulfide oxidoreductase family protein & 10.1 & 5.1 \\
\hline LMOf2365_0861 & Putative endoribonuclease L-PSP & 10.6 & 4.2 \\
\hline LMOf2365_0391 & Messenger RNA biogenesis & 10.7 & 7.8 \\
\hline divIVA LMOf2365_2045 & Cell division protein DivIVA & 14.1 & 5.1 \\
\hline LMOf2365_0997 & Acetyltransferase, GNAT family & 14.5 & 7.1 \\
\hline alsS LMOf2365_2030 & Acetolactate synthase & 16.5 & 20.8 \\
\hline LMOf2365_0640 & Flavodoxin-like fold domain protein & 35.9 & 37.4 \\
\hline \multicolumn{4}{|l|}{ Membrane transport } \\
\hline LMOf2365_0761 & Putative membrane protein & 4.0 & 6.0 \\
\hline LMOf2365_2229 & Oligopeptide ABC transporter, oligopeptide-binding protein & 4.3 & 3.6 \\
\hline LMOf2365_1443 & Transporter, NRAMP family & 5.7 & 6.3 \\
\hline LMOf2365_0168 & Zinc ABC transporter, zinc-binding protein & 6.9 & 52.5 \\
\hline LMOf2365_1435 & Putative transporter & 8.2 & 7.4 \\
\hline LMOf2365_1012 & Membrane protein, TerC family & 9.6 & 257.7 \\
\hline LMOf2365_2330 & Putative membrane protein & 18.9 & 46.3 \\
\hline
\end{tabular}

TABLE 7 | Transcript levels decreased for select genes in response to anaerobiosis at pH 7.5 and 5.5.

\begin{tabular}{|c|c|c|c|}
\hline \multirow[t]{2}{*}{ Gene ID } & \multirow[t]{2}{*}{ Gene product } & \multicolumn{2}{|c|}{ Transcript fold changes } \\
\hline & & pH 7.5 & pH 5.5 \\
\hline \multicolumn{4}{|l|}{ Metabolism } \\
\hline adhE LMOf2365_1656 & Acetaldehyde dehydrogenase/alcohol dehydrogenase & -48.1 & -71.2 \\
\hline LMOf2365_0250 & Serine O-acetyltransferase & -5.8 & -4.4 \\
\hline murE LMOf2365_2070 & UDP-N-acetylmuramoyl-L-alanyl-D-glutamate-2,6-diaminopimelate ligase & -5.7 & -4.5 \\
\hline \multicolumn{4}{|l|}{ Translation } \\
\hline LMOf2365_2879 & tRNA-Glu & -25.3 & -4.8 \\
\hline LMOf2365_2913 & tRNA Leu & -11.5 & -4.1 \\
\hline hly LMOf2365_0213 & Listeriolysin $O$ & -70.0 & -3.7 \\
\hline \multicolumn{4}{|l|}{ Transcription factors } \\
\hline LMOf2365_2205 & Sigma-54 dependent transcriptional regulator & -10.7 & -5.5 \\
\hline
\end{tabular}

(i.e., heat shock, nutrient limitation, acidic condition, etc.) cause an increase in the expression of chaperones (Wright et al., 2016). Indeed, the data showed an increase in the transcript levels of two chaperones (dnaK and $d n a J)$ under anaerobic conditions at both $\mathrm{pH} 7.5$ and 5.5. Therefore, it is possible that L. monocytogenes uses molecular chaperones to combat anaerobic stress, which in 
turn assists with phagocytosis. The gadG encodes for an amino acid antiporter that is part of the glutamate decarboxylase system, which is a defense mechanism up-regulated by L. monocytogenes under acid stress and anaerobiosis. This system alleviates the acidification of the cytoplasm by consuming a proton (Cotter et al., 2001; Jydegaard-Axelsen et al., 2004; Paudyal et al., 2020). The fact that this transcript was up-regulated in response to anaerobic conditions suggests that there may be overlapping functions of the GAD system in both acid resistance and anaerobiosis. The transcript level of the LMOf2365_2333 gene was increased by nearly 9 -fold in comparison to acidic $\mathrm{pH}$. There is a possibility that this amino acid anti-transporter may function with $\operatorname{gad} G$ in response to bile. This should be further explored in future studies.

Transcript levels of eighteen genes were down-regulated under anaerobic conditions regardless of the $\mathrm{pH}$, including histidine kinase, metabolic genes, a universal stress response gene, and genes coding for hypothetical proteins. As histidine kinases are involved in two-component systems, it is possible that suppression of this sensor is responsible for the response to oxygen availability. One of the metabolic genes, the phosphoglycerate mutase, has been shown in Bacillus subtilis to be responsible for the control of the two-component system required for sensing and responding to aerobic and anaerobic respiration (Nakano et al., 1999). The fact that the transcript level of this gene was down-regulated suggests that the accumulation of the product 1,3-bisphosphoglycerate, which is the intermediate in the reaction catalyzed by phosphoglycerate mutase, might impact the regulation of the histidine kinase LMOf2365_2554. The impact of this precursor on regulation of two-component systems needs to be explored in further detail. The transcript level of the gene $a c p P$ was also down-regulated. This gene product is involved in biosynthesis of fatty acids as a lipid transporter. This gene has been found to be differentially regulated under anaerobic conditions in many other bacteria, including Escherichia coli and Neisseria gonorrhoeae (Isabella and Clark, 2011). This indicates that the regulation of the fatty acid synthesis is necessary for the adaptability to anaerobiosis.

\section{Differential Transcript Levels in Response to Anaerobic Acidic Conditions}

An increase in the transcript levels of $n r d D$ (LMOf2365_0299), which is an anaerobic ribonucleoside-triphosphate reductase that catalyzes the synthesis of dNTPs required for DNA replication, was observed under anaerobic conditions at acidic pH. NrdD is an essential enzyme required by L. monocytogenes and other GI pathogens, such as $E$. coli, to survive under anaerobic conditions (Garriga et al., 1996; Ofer et al., 2011). Since our study showed acidic conditions influence the up-regulation of this gene under anaerobic conditions, there is a possibility that this enzyme is involved in growth under acidic conditions. This may be required to stabilize the redox potential of the cell under acidic conditions. Ribonucleotide reductases have been explored as potential biomedical targets for bacterial infections (Torrents, 2014). Since the ribonucleotide reductase was up-regulated under anaerobic acidic conditions, it will be necessary for future studies to analyze the activity of antibacterial compounds under these conditions to effectively target the protein expressed.

Transcript levels of genes coding for a glycosyl hydrolases, which are involved in hydrolyzing the glycosidic linkages in sugars, were also up-regulated. Certain glycosyl hydrolases have been previously identified as virulence factors in gram positive pathogenic bacteria, including Streptococcus pneumoniae (Niu et al., 2013). Glycosyl hydrolase PssZ has been observed to degrade extracellular polymeric substance, thereby disrupting biofilm formation by L. monocytogenes (Wu et al., 2019). L. monocytogenes, which is an intracellular bacterium, may synthesize glycosyl hydrolases upon exposure to acidic $\mathrm{pH}$ under anaerobic conditions, which thereby hinders formation of biofilms and facilitates the bacterium's entry into the host cells.

One of the virulence factors of $L$. monocytogenes is metalloproteases. Few such proteases were identified to have an increase in transcript levels at $\mathrm{pH} 5.5$ in anaerobic conditions, including the aminopeptidase (LMOf2365_2308) (Table 4). It has been shown that the bacterial burden of L. monocytogenes EGDe strain in host cells decreased significantly when the aminopeptidase T of family M29 was deleted (Cheng et al., 2015). Thus, at anaerobic conditions under acidic $\mathrm{pH}$, aminopeptidases may be up-regulated and function as virulence factors.

GalU (LMOf2365_1099), UTP-glucose-1-phosphate uridyltransferase, which catalyzes cell wall teichoic acid glycosylation, had an increase in transcript levels under anaerobic conditions at pH 5.5 (Table 4; Kuenemann et al., 2018). In silico design of GalU inhibitors attenuated virulence of L. monocytogenes, proving GalU to be an instrumental part in virulence pathways (Kuenemann et al., 2018). Various transcription factors were up-regulated under anaerobic conditions at $\mathrm{pH} 5.5$ (Table 4), including the fur regulator that controls virulence of various pathogenic bacteria. We also observed that transcripts coding for virulence genes, such as listeriolysin $\mathrm{O}$ and internalin family proteins, were also up-regulated under these conditions. The transcript level of a methyl accepting chemotaxis protein was also increased. In L. monocytogenes chemotaxis genes cheA and cheY have been shown to facilitate to adhesion and thereby invasion into the host epithelial cells. As L. monocytogenes is an intracellular pathogen, it may be possible that along with the CheA and CheY system, it is using the methyl accepting chemotaxis proteins to attach to epithelial cells under anaerobic conditions at $\mathrm{pH} 5.5$ (Dons et al., 2004).

Internalins $\mathrm{A}$ and $\mathrm{B}$ are required by $L$. monocytogenes for facilitating entry inside host cells. Transcript levels for genes encoding internalin proteins were found to be up-regulated under the acidic environment in absence of oxygen. Interestingly, the transcript level of inlE (LMOf2365_0283), which is a gene coding for the secreted protein Internalin E, was decreased. Internalins $\mathrm{A}$ and $\mathrm{B}$ are involved in adhesion and invasion by Listeria, but Internalin $\mathrm{E}$ is not involved in invasion (Dramsi et al., 1997). This indicates anaerobiosis influences the invasive potential of L. monocytogenes. The impact of anaerobiosis on invasion has been shown in vitro and in vivo, but the exact 
TABLE 8 | Transcript levels increased for select genes in response to bile in anaerobic conditions at $\mathrm{pH}$ 5.5.

\begin{tabular}{lc}
\hline Gene ID Gene product & $\begin{array}{c}\text { Transcript } \\
\text { levels }\end{array}$
\end{tabular}

\section{Metabolism}

LMOf2365_0638

LMOf2365_0686

mvaS LMOf2365_1434

LMOf2365_1406

\section{Pathogenesis}

inlE LMOf2365_0283

LMOf2365_0508

LMOf2365_2725

h/Y-III LMOf2365_1893

LMOf2365_0726

LMOf2365_1503

\section{Cell Signaling}

LMOf2365_0626

Protein Folding

LMOf2365_1018

clpP LMOf2365_2441

trx-1 LMOf2365_1242

clpP-1 LMOf2365_1146

\section{Membrane Transport}

LMOf2365_0153

LMOf2365_0288

LMOf2365_2265

LMOf2365_0295

LMOf2365_1088

LMOf2365_1219

acsA LMOf2365_2700

LMOf2365_2554

LMOf2365_2835

LMOf2365_2647

zurM-2 LMOf2365_1465

LMOf2365_0622

LMOf2365_1002

LMOf2365_0930

LMOf2365_0967

LMOf2365 0810

LMOf2365_1721

LMOf2365_0588

LMOf2365_0701

ImrB-2 LMOf2365_2560

LMOf2365_1695

LMOf2365_2119

LMOf2365_2222

LMOf2365_0570

LMOf2365_0812

LMOf2365_0941
Rhodanese-like domain protein

Serine/threonine protein phosphatase

family protein

Hydroxymethylglutaryl-CoA synthase

Putative pyrroline-5-carboxylate

reductase

Internalin E

Putative antigen

CBS domain protein

Hemolysin III

Flagellin

DNA-binding protein, ComEA family

Cyclic nucleotide-binding protein

ATP-dependent Clp protease,

ATP-binding subunitE

ATP-dependent Clp protease, protease

subunit

Thioredoxin

ATP-dependent Clp protease,

proteolytic subunit $\mathrm{P}$

\section{Oligopeptide ABC transporter}

Putative transporter

CBS domain protein

Competence protein

ComEC/Rec2-related protein

Cell division protein, FtsW/RodA/SpoVE

family

Putative membrane protein

Acetyl-coenzyme A synthetase

Sensor histidine kinase

Major facilitator family transporter

PTS system, IIA component

Zinc ABC transporter, permease protein

Formate/nitrite transporter family

protein

Drug resistance transporter,

EmrB/QacA family

Putative membrane protein

Putative transporter

Putative membrane protein

Cation efflux family protein

Magnesium transporter, CorA family

ABC transporter, ATP-binding protein

Lincomycin resistance protein LmrB

Putative laminin-binding surface protein

MATE efflux family protein

CoiA-like family protein

ABC transporter, substrate-binding

protein

RarD protein

ABC transporter, ATP-binding protein
TABLE 8 | (Continued)

\begin{tabular}{llc}
\hline Gene ID & Gene product & $\begin{array}{c}\text { Transcript } \\
\text { levels }\end{array}$ \\
\hline LMOf2365_1011 & MATE efflux family protein & 19.1 \\
LMOf2365_0167 & $\begin{array}{l}\text { Bacterial extracellular solute-binding } \\
\text { protein }\end{array}$ & 20.4 \\
& Zinc-binding, ComEB family protein & 21.8 \\
LMOf2365_1502 & Major facilitator family transporter & 25.6 \\
LMOf2365_1000 & ABC transporter, ATP-binding protein & 46.6 \\
LMOf2365_0034 & Putative membrane protein & 60.2
\end{tabular}

Replication and Repair

LMOf2365_0196

LMOf2365_1533

LMOf2365_1998

LMOf2365_0949

Deoxyribonuclease, TatD family

3.1

ATPase, AAA family domain protein

3.3

Putative DNA-damage-inducible protein

4.2

5.2

6.2

29.2

130.5

rnhA LMOf2365_1909

LMOf2365_2784

Putative DNA-3-methyladenine

4.7

glycosylase

Ribonuclease HI

4.9

dbpA LMOf2365_1260

recA LMOf2365 1417

Replication and repair

ATP-dependent RNA helicase DbpA

Recombination protein RecA

LMOf2365_0863

LMOf2365 2339

LMOf2365_0849

dnaG LMOf2365_1474

Transcription Factors

LMOf2365_1427

LMOf2365_1515

nusG LMOf2365_0258

LMOf2365_2467

LMOf2365_2223

LMOf2365_0023

LMOf2365_0576

LMOf2365_2337

ctsR LMOf2365_0241

LMOf2365_0119

LMOf2365_0446

LMOf2365_2017

LMOf2365_2841

LMOf2365_1051

LMOf2365_0906

LMOf2365_0794

LMOf2365 2466

LMOf2365_2669

LMOf2365_0266

LMOf2365_0665

LMOf2365 0841

LMOf2365_0394

LMOf2365_1894

LMOf2365_2224

LMOf2365_0940

LMOf2365_2322

LMOf2365_0435

LMOf2365_2799
Excinuclease $\mathrm{ABC}$ subunit $\mathrm{C}$ domain protein

MutT/nudix family protein

Putative transposase OrfA, IS3 family

DNA primase

Transcriptional regulator, PadR family

Transcription elongation factor GreA

Transcription antitermination factor

NusG

Phosphate transport system protein

Phol

MecA family protein

Transcriptional regulator, GntR family

Putative DNA-binding transcriptional regulator

Transcriptional regulator, DeoR family

Transcriptional regulator CtsR

Transcriptional regulator, ArsR family

Transcriptional regulator, LysR family

Transcriptional regulator, Lacl family

Transcriptional regulator, AraC family

Transcriptional regulator, Lacl family

Conserved hypothetical protein

ROK family protein

Transcriptional regulator, ArsR family

Transcriptional regulator, TetR family

Transcriptional regulator, DegA family

Rrf2 family protein

Transcriptional regulator, MerR family

Transcriptional regulator, DeoR family

DeoR family transcriptional regulator,

catabolite repression regulator

ArsC family protein

PRD/PTS system IIA 2 domain protein

LysR family transcriptional regulator,

regulator of the ytml operon

DNA-binding protein
DNA-binding protein
5.9

8.4

9.2

11.4

11.6

12.7

18.7

3.3

3.4

3.4

3.4

3.6

3.6

3.6

3.7

3.8

4.0

4.0

4.1

4.4

4.4

4.8

5.1

5.8

5.8

6.1

6.5

7.7

9.5

11.5

11.7

12.4

13.1

14.2

14.7 
TABLE 8 | (Continued)

\begin{tabular}{llc}
\hline Gene ID & Gene product & $\begin{array}{c}\text { Transcript } \\
\text { levels }\end{array}$ \\
\hline LMOf2365_1010 & Transcriptional regulator, MarR family & 18.4 \\
LMOf2365_2233 & Transcriptional regulator, MarR family & 19.1 \\
LMOf2365_0755 & Transcriptional regulator, PadR family & 19.5 \\
LMOf2365_0387 & GntR family transcriptional regulator & 25.7 \\
LMOf2365_0326 & DNA-binding protein & 41.2 \\
\hline
\end{tabular}

mechanism of such interplay has not been well characterized (Bo Andersen et al., 2007; Harris et al., 2019).

\section{Differential Transcript Levels in Response to Bile Under Anaerobic Conditions}

Previous studies have shown that following ingestion of L. monocytogenes into host systems, the prfA regulon is upregulated (Scortti et al., 2007). prfA, the positive regulatory factor $\mathrm{A}$, is a transcription factor that regulates major virulence factors of $L$. monocytogenes. prfA regulates listeriolysin $\mathrm{O}$, phospholipase $\mathrm{C}$ and metalloproteases, all of which were upregulated in anaerobiosis in presence of bile (Table 6). Following bile exposure, the transcript levels of the virulence regulator $\operatorname{prfA}$ were decreased (Boonmee et al., 2019); however these data show that under anaerobic conditions in presence of bile, $\operatorname{prfA}$ is up-regulated independent of $\mathrm{pH}$. We have also observed that L. monocytogenes survives bile better under anaerobic conditions (Figure 2).

Previous transcriptomics studies in L. monocytogenes 10403S (Boonmee et al., 2019) have found that following exposure to bile, the house keeping sigma factor $\sigma^{\mathrm{A}}$ has a significant role in survival. marR [multiple antibiotic resistance regulator (LMOf2365_0641)] is a transcriptional regulator that was upregulated in response to bile in anaerobic conditions regardless of the $\mathrm{pH}$ tested (Table 6). In pathogens such as Salmonella and Staphylococcus, marR homologs slyA and sarZ regulate virulence gene expression. $\operatorname{mar} R$ homologs have also been found to regulate genes involved in stress response, degradation or efflux of harmful substances and metabolic pathways (Grove, 2013). Bile exposure under anaerobic environments may trigger the up-regulation of marR to export bile out of the bacterial cell, thereby contributing to the bile resistance of L. monocytogenes along with other factors. The role of marR in bile resistance needs to be further explored.

Glutamine synthetase catalyzes the condensation of ammonia and glutamate to form glutamine. The transcript level of the glutamine synthetase repressor, $g \ln R$ (LMOf2365_1316) was increased following exposure to bile in anaerobic conditions. It is a central nitrogen metabolism regulator which is activated in presence of glutamine. When glutamine is in excess, GlnR represses the synthesis of glutamine synthetase (Kaspar et al., 2014). Another probable transcriptional regulator ( $\operatorname{tnr} A$ or $\operatorname{cod} Y$ ) represses glutamine synthetase and its activation have been found to be essential in replication Listeria intracellularly (Kaspar et al., 2014). Interestingly glutamine synthetase was also up-regulated
TABLE 9 | Transcript levels decreased for select genes in response to bile in anaerobic conditions at $\mathrm{pH} 5.5$.

\begin{tabular}{|c|c|c|}
\hline Gene ID & Gene name & $\begin{array}{l}\text { Transcript } \\
\text { levels }\end{array}$ \\
\hline \multicolumn{3}{|l|}{ Metabolism } \\
\hline LMOf2365_2610 & Putative lipoprotein & -29.9 \\
\hline LMOf2365_0802 & FMN-dependent NADH-azoreductase & -21.6 \\
\hline LMOf2365_1226 & Putative peptidase & -18.2 \\
\hline LMOf2365_0565 & 6-phospho-beta-glucosidase & -18.2 \\
\hline pflA LMOf2365_1426 & $\begin{array}{l}\text { Pyruvate formate lyase activating } \\
\text { enzyme }\end{array}$ & -11.1 \\
\hline LMOf2365_1975 & Riboflavin transporter & -10.2 \\
\hline pyrH LMOf2365_1330 & Uridylate kinase & -8.7 \\
\hline LMOf2365_1597 & $\begin{array}{l}\text { Bifunctional oligoribonuclease and PAP } \\
\text { phosphatase NrnA }\end{array}$ & -8.5 \\
\hline LMOf2365_0277 & Glycosyl hydrolase, family 1 & -8.5 \\
\hline LMOf2365_0776 & Hydrolase, alpha/beta fold family & -8.2 \\
\hline pfl-2 LMOf2365_1946 & Formate C-acetyltransferase & -8.2 \\
\hline rp/S LMOf2365_1814 & Large subunit ribosomal protein L19 & -7.7 \\
\hline pepQ LMOf2365_1600 & Proline dipeptidase & -7.6 \\
\hline cadA LMOf2365_0672 & Zn2+/Cd2+-exporting ATPase & -7.6 \\
\hline LMOf2365_2666 & $\begin{array}{l}\text { Cell division protein, FtsW/RodA/SpoVE } \\
\text { family }\end{array}$ & -7.3 \\
\hline LMOf2365_0021 & Glycosyl hydrolase, family 1 & -6.9 \\
\hline LMOf2365_2146 & $\begin{array}{l}\text { Hydrogen peroxide-dependent heme } \\
\text { synthase }\end{array}$ & -6.5 \\
\hline glmS LMOf2365_0762 & $\begin{array}{l}\text { Glutamine-fructose-6-phosphate } \\
\text { transaminase }\end{array}$ & -6.3 \\
\hline LMOf2365_1093 & N-acetylmuramoyl-L-alanine amidase & -6.3 \\
\hline LMOf2365_0057 & Accessory gene regulator $B$ & -5.9 \\
\hline LMOf2365_1386 & Phosphate butyryltransferase & -5.7 \\
\hline thil LMOf2365_1614 & tRNA uracil 4-sulfurtransferase & -5.7 \\
\hline galU LMOf2365_1099 & $\begin{array}{l}\text { UTP-glucose-1-phosphate } \\
\text { uridylyltransferase }\end{array}$ & -5.6 \\
\hline LMOf2365_1702 & $\begin{array}{l}\text { Methionine } \\
\text { synthase/methylenetetrahydrofolate } \\
\text { reductase (NADPH) }\end{array}$ & -5.6 \\
\hline LMOf2365_2609 & FAD:protein FMN transferase & -5.6 \\
\hline eno LMOf2365_2428 & Enolase & -5.5 \\
\hline LMOf2365_2670 & $\begin{array}{l}\mathrm{N} \text {-acetylmuramoyl-L-alanine amidase, } \\
\text { family } 4\end{array}$ & -5.3 \\
\hline fabl LMOf2365_0990 & Enoyl-[acyl-carrier-protein] reductase I & -5.2 \\
\hline LMOf2365_1880 & $\begin{array}{l}\text { Copper chaperone; heavy metal } \\
\text { binding protein }\end{array}$ & -5.1 \\
\hline LMOf2365_2711 & PhnB protein & -5.1 \\
\hline LMOf2365_2673 & Orn/Lys/Arg decarboxylase & -5.1 \\
\hline LMOf2365_1368 & Rhodanese-like domain protein & -5.0 \\
\hline LMOf2365_2510 & UDP-N-acetylglucosamine 2-epimerase & -4.8 \\
\hline mraY LMOf2365_2069 & $\begin{array}{l}\text { Phospho-N-acetylmuramoyl- } \\
\text { pentapeptide-transferase }\end{array}$ & -4.7 \\
\hline purA LMOf2365_0065 & Adenylosuccinate synthase & -4.7 \\
\hline ald LMOf2365_1601 & Alanine dehydrogenase & -4.7 \\
\hline plcA LMOf2365_0212 & $\begin{array}{l}\text { 1-phosphatidylinositol } \\
\text { phosphodiesterase }\end{array}$ & -4.6 \\
\hline menE LMOf2365_1696 & O-succinylbenzoate-CoA ligase & -4.6 \\
\hline murC LMOf2365_1627 & UDP-N-acetylmuramate-alanine ligase & -4.5 \\
\hline LMOf2365_2743 & Hydrolase, CocE/NonD family & -4.4 \\
\hline gpmA LMOf2365_2429 & $\begin{array}{l}\text { 2,3-bisphosphoglycerate-independent } \\
\text { phosphoglycerate mutase }\end{array}$ & -4.4 \\
\hline LMOf2365_0434 & $\begin{array}{l}\text { Peptidoglycan-N-acetylglucosamine } \\
\text { deacetylase }\end{array}$ & -4.1 \\
\hline
\end{tabular}


TABLE 9 | (Continued)

\begin{tabular}{|c|c|c|}
\hline Gene ID & Gene name & $\begin{array}{l}\text { Transcript } \\
\text { levels }\end{array}$ \\
\hline tmk LMOf2365_2672 & Thymidylate kinase & -4.1 \\
\hline LMOf2365_1643 & 8-oxo-dGTP diphosphatase & -4.1 \\
\hline LMOf2365_2133 & $\begin{array}{l}\text { Pyridoxal 5'-phosphate synthase pdxS } \\
\text { subunit }\end{array}$ & -3.9 \\
\hline pyk LMOf2365_1592 & Pyruvate kinase & -3.9 \\
\hline alaS LMOf2365_1523 & Alanyl-tRNA synthetase & -3.9 \\
\hline fhs LMOf2365_1906 & Formate-tetrahydrofolate ligase & -3.9 \\
\hline LMOf2365_1033 & $\mathrm{N}$-acetyldiaminopimelate deacetylase & -3.8 \\
\hline LMOf2365_0872 & D-alanine-D-alanine ligase & -3.8 \\
\hline LMOf2365_0987 & Putative GTP pyrophosphokinase & -3.8 \\
\hline LMOf2365_1299 & Acyl-CoA thioester hydrolase & -3.8 \\
\hline LMOf2365_1512 & Peptidase, M3 family & -3.7 \\
\hline pfl-1 LMOf2365_1425 & Formate C-acetyltransferase & -3.7 \\
\hline LMOf2365_2144 & Nitroreductase family protein & -3.6 \\
\hline folA LMOf2365_1903 & Dihydrofolate reductase & -3.6 \\
\hline LMOf2365_1371 & Xaa-Pro aminopeptidase & -3.6 \\
\hline upp LMOf2365_2511 & Uracil phosphoribosyltransferase & -3.5 \\
\hline uppS LMOf2365_133 & Undecaprenyl diphosphate synthase & -3.5 \\
\hline LMOf2365_0239 & Dihydrouridine synthase family protein & -3.5 \\
\hline LMOf2365_1633 & Putative glutamyl-aminopeptidase & -3.4 \\
\hline LMOf2365_1476 & $\begin{array}{l}\text { [pyruvate, water dikinase]-phosphate } \\
\text { phosphotransferase }\end{array}$ & -3.4 \\
\hline LMOf2365_0293 & Acetyltransferase, GNAT family & -3.4 \\
\hline LMOf2365_1691 & L-lactate dehydrogenase & -3.3 \\
\hline LMOf2365_0101 & $\begin{array}{l}\text { Oxidoreductase, aldo/keto reductase } \\
\text { family }\end{array}$ & --3.3 \\
\hline LMOf2365_1644 & $\begin{array}{l}\text { ADP-dependent NAD(P)H-hydrate } \\
\text { dehydratase }\end{array}$ & -3.3 \\
\hline LMOf2365_0846 & $\begin{array}{l}\text { Pyruvate-ferredoxin/flavodoxin } \\
\text { oxidoreductase }\end{array}$ & -3.3 \\
\hline LMOf2365_1915 & Carboxypeptidase Taq & -3.3 \\
\hline hemE LMOf2365_2245 & Uroporphyrinogen decarboxylase & -3.3 \\
\hline nrdD LMOf2365_0299 & Ribonucleoside-triphosphate reductase & -3.3 \\
\hline sdhB LMOf2365_1841 & L-serine dehydratase & -3.3 \\
\hline LMOf2365_2207 & $\begin{array}{l}\text { Oxidoreductase, short-chain } \\
\text { dehydrogenase/reductase family }\end{array}$ & -3.2 \\
\hline LMOf2365_2514 & L-threonylcarbamoyladenylate synthase & -3.2 \\
\hline pepT LMOf2365_1805 & Tripeptide aminopeptidase & -3.1 \\
\hline LMOf2365_1048 & Ribonuclease J & -3.1 \\
\hline mpl LMOf2365_0214 & Zinc metalloproteinase & -3.1 \\
\hline LMOf2365_0488 & Undecaprenyl diphosphate synthase & -3.1 \\
\hline LMOf2365_2308 & Bleomycin hydrolase & -3.1 \\
\hline manA LMOf2365_2143 & $\begin{array}{l}\text { Mannose-6-phosphate isomerase, } \\
\text { class I }\end{array}$ & -3.0 \\
\hline ftsX LMOf2365_2479 & $\begin{array}{l}\text { Cell division ABC transporter, permease } \\
\text { protein FtsX }\end{array}$ & -3.0 \\
\hline gap LMOf2365_2432 & $\begin{array}{l}\text { Glyceraldehyde 3-phosphate } \\
\text { dehydrogenase }\end{array}$ & -3.0 \\
\hline \multicolumn{3}{|l|}{ Pathogenesis } \\
\hline plcB LMOf2365_0216 & Phospholipase C & -10.0 \\
\hline LMOf2365_1812 & Internalin family protein & -6.1 \\
\hline \multicolumn{3}{|c|}{ Replication and repair } \\
\hline dnaE LMOf2365_1596 & DNA polymerase III subunit alpha & -4.9 \\
\hline LMOf2365_1628 & $\begin{array}{l}\text { DNA segregation ATPase FtsK/SpollIE, } \\
\text { S-DNA-T family }\end{array}$ & -4.3 \\
\hline ligA LMOf2365_1783 & DNA ligase, NAD-dependent & -3.2 \\
\hline recG LMOf2365_1839 & ATP-dependent DNA helicase RecG & -3.0 \\
\hline
\end{tabular}

TABLE 9 | (Continued)

\begin{tabular}{|c|c|c|}
\hline Gene ID & Gene name & $\begin{array}{l}\text { Transcript } \\
\text { levels }\end{array}$ \\
\hline \multicolumn{3}{|l|}{ Transcription factor } \\
\hline LMOf2365_2335 & Transcriptional regulator, RofA family & -8.6 \\
\hline $\arg R$ LMOf2365_1384 & Arginine repressor & -4.4 \\
\hline LMOf2365_2715 & Transcriptional regulator, MerR family & -3.4 \\
\hline LMOf2365_2780 & DNA-binding protein & -3.2 \\
\hline \multicolumn{3}{|l|}{ Membrane transport } \\
\hline LMOf2365_2388 & $\begin{array}{l}\text { D-methionine transport system } \\
\text { substrate-binding protein }\end{array}$ & -9.1 \\
\hline LMOf2365_0606 & Putative membrane protein & -8.4 \\
\hline Ffh LMOf2365_1828 & $\begin{array}{l}\text { Signal recognition particle subunit } \\
\text { SRP54 }\end{array}$ & -7.3 \\
\hline LMOf2365_2553 & $\begin{array}{l}\text { Putative ABC transport system } \\
\text { permease protein }\end{array}$ & -6.3 \\
\hline ptsl LMOf2365_1024 & $\begin{array}{l}\text { Phosphoenolpyruvate-protein } \\
\text { phosphotransferase }\end{array}$ & -5.9 \\
\hline LMOf2365_0803 & D-serine/D-alanine/glycine transporter & -5.8 \\
\hline agrC LMOf2365_0059 & $\begin{array}{l}\text { Two-component system, LytTR family, } \\
\text { sensor histidine kinase AgrC }\end{array}$ & -5.1 \\
\hline LMOf2365_0673 & Putative membrane protein & -4.4 \\
\hline cydD LMOf2365_2695 & $\begin{array}{l}\text { ATP-binding cassette, subfamily } C \text {, } \\
\text { bacterial CydC }\end{array}$ & -4.3 \\
\hline LMOf2365_1034 & $\begin{array}{l}\text { Moderate conductance } \\
\text { mechanosensitive channel }\end{array}$ & -4.3 \\
\hline prf1 LMOf2365_2516 & Peptide chain release factor 1 & -4.2 \\
\hline Idh-1 LMOf2365_0221 & L-lactate dehydrogenase & -4.2 \\
\hline LMOf2365_2148 & ABC transporter, permease protein & -4.0 \\
\hline LMOf2365_1450 & ABC transporter, ATP-binding protein & -3.8 \\
\hline LMOf2365_1994 & $\begin{array}{l}\text { ABC-2 type transport system } \\
\text { ATP-binding protein }\end{array}$ & -3.8 \\
\hline LMOf2365_1264 & Putative transporter & -3.3 \\
\hline LMOf2365_2323 & Monovalent cation/hydrogen antiporter & -3.2 \\
\hline LMOf2365_0845 & $\mathrm{Na} / \mathrm{Pi}$-cotransporter family protein & -3.2 \\
\hline LMOf2365_1091 & $\begin{array}{l}\text { Teichoic acid transport system } \\
\text { permease protein }\end{array}$ & -3.1 \\
\hline LMOf2365_2844 & $\begin{array}{l}\text { YidC/Oxa1 family membrane protein } \\
\text { insertase }\end{array}$ & -3.0 \\
\hline LMOf2365_0317 & Putative membrane protein & -3.0 \\
\hline \multicolumn{3}{|l|}{ Translation } \\
\hline tsf LMOf2365_1678 & Elongation factor Ts & -11.4 \\
\hline rpsB LMOf2365_1679 & Small subunit ribosomal protein S2 & -5.4 \\
\hline valS LMOf2365_1573 & Valyl-tRNA synthetase & -4.1 \\
\hline gatB MOf2365_1779 & $\begin{array}{l}\text { Aspartyl-tRNA(Asn)/glutamyl-tRNA(GIn) } \\
\text { amidotransferase subunit B }\end{array}$ & -4.1 \\
\hline efp LMOf2365_1372 & Translation elongation factor $\mathrm{P}$ & -3.4 \\
\hline thrS LMOf2365_1580 & Threonyl-tRNA synthetase & -3.1 \\
\hline infA LMOf2365_2583 & Translation initiation factor IF-1 & -3.1 \\
\hline
\end{tabular}

under the same conditions, which indicates the possibility of a feedback loop.

Metalloenzyme carbonic acid catalyzes hydration of carbon dioxide into bicarbonate and proton (Supuran, 2016). The infection cycle of Legionella has similarities with that of L. monocytogenes, such as invasion and escaping the phagosome. Legionella has been shown to evade the destruction by maintaining neutral $\mathrm{pH}$ (Supuran, 2016). One of the enzymes involved in regulating the $\mathrm{pH}$ is carbonic anhydrase; the transcript level of carbonic anhydrase increased under anaerobic 
conditions in the presence of bile in L. monocytogenes (Table 6). This could indicate that environmental conditions mimicking parts of intestine can contribute to Listeria's pathogenic potential. Interestingly, the transcript level of this gene was down-regulated under acidic conditions (Table 5), suggesting that the influence of bile is important to the expression of this gene.

Transcript levels representative of an uncharacterized membrane protein LMOf2365_1012 that belongs to the TerC family was up-regulated following exposure to bile in anaerobic conditions (Table 6). In B. subtilis, TerC has been found to confer manganese resistance (Paruthiyil et al., 2020). In Streptococcus, manganese homeostasis is linked to oxidative stress as well as virulence (Turner et al., 2015). It is possible that TerC is linked with manganese homeostasis and therefore virulence in the presence of bile under anaerobic conditions. Transcripts coding for several other membrane transporters were also increased in their levels under the anaerobic environment in response to bile. The zinc $\mathrm{ABC}$ transporter has been shown to have a role in virulence of $L$. monocytogenes in a mouse infection model (Corbett et al., 2012). Thus, bile exposure in absence of oxygen probably impacts uptake of zinc by the bacteria thereby impacting the virulence. NRAMP, which functions as a metal ion transporter on membranes, was up-regulated (Nevo and Nelson, 2006).

The transcript level of the oligopeptide $\mathrm{ABC}$ transporter, which is an oligopeptide binding protein that helps the bacteria survive intracellularly, was increased (Slamti and Lereclus, 2019). It is the substrate binding component or receptor of an $\mathrm{ABC}$ type oligopeptide transport system that binds extracellular peptides, relays it to the membrane component of the system and inside the bacterial cell afterward. Gram positive bacteria such as Listeria, Streptococcus, and Enterococcus, use peptides to sense and respond to environmental changes. The gene $о p p A$, which encodes for an oligopeptide binding protein, has been found to be required for invasion (Borezee et al., 2000). Thus, the oligopeptide $\mathrm{ABC}$ transporter observed in our study could be responsible for intracellular survival of bacteria in presence of bile under anaerobic conditions.

Interestingly, there was a decrease in the transcript levels of $h l y$ (LMOf2365_0213), which encodes for listeriolysin O, at both $\mathrm{pH}$ 7.5 and 5.5 following exposure to bile under anaerobic conditions. This was different than what was observed under anaerobiosis at $\mathrm{pH} 5.5$ alone, as hly (LMOf2365_0213) was up-regulated in these conditions (Table 4). This suggests that bile has an important role in regulating the invasiveness of $L$. monocytogenes. This correlates well with previous studies that have shown that L. monocytogenes remains extracellular in the gall bladder, which has high concentrations of bile (Hardy et al., 2004; Dowd et al., 2011).

\section{Differential Transcript Levels in Response to Bile Under Acidic and Anaerobic Conditions}

There was an increase in transcript levels for the myosin cross reactive antigen (McrA) (LMOF2365_0508; Table 8). Although its function in L. monocytogenes is yet unknown, in Streptococcus pyogenes McrA is a fatty acid double bond hydratase that adds water to double bonds of fatty acids. Upon deletion of this gene, decreased oleic acid resistance and reduced adherence and internalization in the host cell was observed in S. pyogenes (Volkov et al., 2010). Conditions encountered within the duodenum may directly or indirectly contribute to up-regulation of $m c r A$, which may regulate the pathogen's resistance to bile.

Internalin $\mathrm{E}$ and hemolysin III are both virulence factors responsible for internalization and invasion for L. monocytogenes. Both had an increase in transcript levels, indicating that bile exposure at acidic and anaerobic conditions, which mimics the duodenum, is conducive to the pathogenesis of the bacteria.

The transcript level of the LPXTG-motif cell wall anchor domain (LMOF2365_1144) was also up-regulated. In the L. monocytogenes EGDe strain, it has been shown that a LPXTG protein encoded by the Listeria mucin binding invasion A gene, or $\operatorname{lmiA}$, has roles in promoting bacterial adhesion and entry into the host cell (Mariscotti et al., 2014). MucBP domain present in LPXTG was observed to bind to mucin. Thus, up-regulation of LPXTG gene under conditions mimicking the duodenum indicates that these conditions may facilitate invasion of host cells by the bacteria.

The level of transcripts representing flagellin also increased. It has been shown that flagellin helps in motility soon after ingestion in vivo (O'Neil and Marquis, 2006) and invasion (Dons et al., 2004). A previous study has also observed up-regulation of motility under exposure to bile at pH 5.5 (Guariglia-Oropeza et al., 2018). The fact that expression increased in conditions that would be encountered soon after ingestion suggests that the flagellin are important for the motility of the bacteria to the location in the GI tract where they will invade the intestinal lining.

The transcript level of the histidine kinase LMOf2365_2554 was also up-regulated under conditions mimicking the duodenum. Histidine kinase is the signal receiver a twocomponent regulatory system. Its counterpart in the system is the response regulator (Chang and Stewart, 1998; Stock et al., 2000; West and Stock, 2001; Krell et al., 2010). Response regulators in L. monocytogenes have been proven to have roles in virulence and pathogenesis. Sensor histidine kinase, ChiS, regulates the chitin utilization pathway required by Vibrio cholerae, which is needed to survive in aquatic environments. Chourashi et al. (2016) observed that ChiS has an important role in adherence and intracellular survival of $V$. cholerae in HT-29 cell cultures. They also showed that the sensor histidine kinase ChiS was activated in the presence of intestinal mucin (Chourashi et al., 2016). In the case of L. monocytogenes, it could be possible that the conditions in the duodenum are favorable for activation of the sensor histidine kinase, which could in turn relay information that would result in the activation of transcription factors responsible for adhesion and invasion.

Transcript levels representative of replication and repair genes were also up-regulated. In L. monocytogenes strain EGDe, RecA has been shown to have roles in bile and acid resistance, as well as in adhesion and invasion to Caco-2 cell cultures (van der Veen and Abee, 2011). Our data indicate that in the pathogenic strain F2365, RecA has the similar role of bile and acid 
resistance. In our study, we have also found that under anaerobic conditions (along with bile and acidic) the transcript level of recA changed, indicating absence of oxygen may have impact on activation of RecA.

The transcript level for a gene encoding for the transcriptional regulator $p a d R$ was up-regulated (Table 8). In L. monocytogenes EGDe, LftR, which is a PadR like transcriptional regulator, has been shown to influence invasion of human host cells (Kaval et al., 2015). It is already known that Listeria uses internalin proteins for adhering and internalizing into the cell. Kaval et al. (2015) found that LftR, which is an uncharacterized protein, is required for invasion.

Transcript level of the gene encoding for $c t s R$, (LMOf2365_0241) a class III stress gene repressor that negatively regulates $c l p$, was up-regulated under these conditions (Table 8). CtsR has been shown to be required for virulence in mice. PrfA which regulates many virulence genes of $L$. monocytogenes has been shown to down-regulate ClpC production (Karatzas et al., 2003). Although Karatzas et al. (2003) could not find any relationship between $c l p$ and $p r f A$, there is still a possibility that there is a connection between the regulation of Clp by CtsR under anaerobic conditions in exposure to bile at acidic $\mathrm{pH}$ (Cui et al., 2018).

The transcript level of the transcription elongation factor greA (LMOf2365_1515) also increased under anaerobic conditions with acidic bile. GreA has been found to have roles in affecting functions of virulence gene expression in the pathogen Francisella tularensis subsp. Novicida (Cui et al., 2018). In F. tularensis, GreA was found to be required for invasion and intracellular growth of bacteria. Cui et al. (2018) also observed suppression of virulence of the greA mutant in mouse model. Transcriptomics analysis of the greA mutant revealed down-regulation of various genes responsible for virulence. Thus, with respect to our work, conditions in the duodenum are favorable for induction of the transcription elongation factor greA, which may in turn regulate genes responsible for invasion and multiplication of L. monocytogenes.

This study indicates that not only one stressor, but combinations of different stressors impact the transcription of various virulence genes. Transcriptomic and phenotypic studies in absence of these genes under mimicking physiological condition could give us an insight into this mechanism. A better understanding of how these biological processes help the survival of L. monocytogenes will lead us to understand how the physiological conditions contribute to the pathogenesis.

\section{MATERIALS AND METHODS}

\section{Bacterial Strain and Culture Conditions}

Listeria monocytogenes str. 4b F2365 was used for this study. Overnight cultures of L. monocytogenes str. 4b F2365 were grown at $37^{\circ} \mathrm{C}$ aerobically in Brain Heart Infusion (BHI) media at $\mathrm{pH}$ 7.5. Next day, inoculum (1:100) from the overnight culture was used to grow the cells to mid exponential phase in fresh $\mathrm{BHI}$ media $\left(\mathrm{OD}_{600}=0.3\right.$ to 0.5$)$ under either aerobic or anaerobic conditions in $5 \mathrm{~mL}$ aliquots. Anaerobic culture conditions were obtained using an incubator shaker set at $37^{\circ} \mathrm{C}$ inside a Coy Anaerobic Chamber with a gas mixture of $95 \% \mathrm{~N}_{2}$ and $5 \%$ $\mathrm{H}_{2}$ (Coy Laboratory Products, United States). Cells were then pelleted at $8000 \times g$ at $23^{\circ} \mathrm{C}$ and resuspended in fresh BHI at a $\mathrm{pH}$ of either 7.5 or 5.5; $\mathrm{pH}$ was adjusted with either $\mathrm{HCl}$ or $\mathrm{NaOH}$. For bile treated cells, mid exponential phase cells were resuspended in $\mathrm{BHI}$ at a $\mathrm{pH}$ of either 7.5 or 5.5 supplemented with $1 \%$ porcine bile extract (Sigma Aldrich, United States). Cells were then grown under either aerobic or anaerobic conditions at $37^{\circ} \mathrm{C}$. This study had eight different conditions that mimicked parts of the GI tract. The conditions tested were: (1) aerobic at $\mathrm{pH} 5.5$; (2) anaerobic at $\mathrm{pH} 5.5$; (3) aerobic at $\mathrm{pH} 7.5$; (4) anaerobic at $\mathrm{pH} 7.5$; (5) aerobic at $\mathrm{pH} 5.5$ with $1 \%$ porcine bile; (6) anaerobic at $\mathrm{pH} 5.5$ with $1 \%$ porcine bile; (7) aerobic at $\mathrm{pH}$ 7.5 with $1 \%$ porcine bile; and (8) anaerobic at $\mathrm{pH} 7.5$ with $1 \%$ porcine bile. For each time point during a $7 \mathrm{~h}$ incubation period, aliquots were serially diluted in phosphate buffered saline (PBS) and plated onto BHI agar plates. Plates were incubated overnight at $37^{\circ} \mathrm{C}$ prior to enumeration. Three independent replicates were performed in parallel for each individual condition tested.

\section{RNA Extraction, Library Preparation and RNA Sequencing}

To isolate the RNA for analysis of the transcript level expression, cells were collected after $1 \mathrm{~h}$ of incubation in the eight culture conditions described above. Three biological replicates were assayed. Briefly, $5 \mathrm{~mL}$ of culture was pelleted by centrifugation at $8,000 \times g$ for $5 \mathrm{~min}$ at room temperature. Cell pellets were then treated with RNA Protect Bacterial Reagent (Qiagen, Germany). Total RNA was isolated using the RNeasy ${ }^{\circledR}$ Mini Kit (Qiagen, Germany) per manufacturer's instructions. The extracted RNA was quantitated using Qubit 3 Fluorometer (Invitrogen, United States) using the Qubit RNA BR assay kit (Thermo Fisher, United States). Extracted samples with values of A260/280 2.0 were selected for sequencing. Illumina HiSeq $^{\text {TM }} 2000$ paired-end 50 bp sequencer (PE50) was used. Ribosomal RNA was reduced with Epicentre RiboMinus kit (Illumina, United States) coupled with Directional RNA-Seq library prep with TruSeq indexes (Illumina, United States) per manufacturer's instructions.

\section{Data Analysis}

Differences in survival were determined using a student's $t$-test (Prism 8). Tophat-2.0.8.b (Trapnell et al., 2009) was used to align the RNA-Seq data to the reference genome, AE017262.2 L. monocytogenes str. 4b F2365. Transcript level calculation and FPKM normalization were performed using Cufflinks2.1.1 (Trapnell et al., 2010). FPKM filtering cutoff of 1.0 was maintained to determine expressed transcripts. Differential transcript levels of the genes were determined using Cuffdiff (Trapnell et al., 2013). Differential transcript levels which had a greater than 3-fold expression and were statistically significant $(p<0.01$ and $q<0.01)$ were subjected to Gene Ontology (GO) enrichment analysis using Blast2GO (Conesa et al., 2005). In this software, the up- and down-regulated transcripts were selected, and BLAST was performed against the L. monocytogenes 
nucleotide database in NCBI. The BLAST results were then mapped and annotated.

\section{DATA AVAILABILITY STATEMENT}

SRA IDs of the submitted data: SRR13859772, SRR13859774, and SRR13859773: F2365 pH 5.5 Aerobic, SRR13859144, SRR13859143, and SRR13859142: F2365 pH 5.5 Anaerobic, SRR13859527, SRR13859526, and SRR13859525: F2365 pH 5.5+ Bile Anaerobic, SRR13859600, SRR13859599, and SRR13859598: F2365 pH 7.5+ Bile aerobic, SRR13858938, SRR13858937, and SRR13858936: F2365 pH 7.5+ Bile Anaerobic, SRR13858765, SRR13858767, and SRR13858766: F2365 pH 7.5 Anaerobic, SRR13853432, SRR13853433, and SRR13853431: F2365 pH 5.5+ Bile Aerobic, SRR13849951, SRR13849952, and SRR13849950: F2365 pH 7.5 aerobic.

\section{AUTHOR CONTRIBUTIONS}

JD: conceptualization, supervision, and project administration. MA, MD, JD, GS, and DC: methodology. GS and DC: software. GS, DC, and JD: validation and visualization. DC and JD: investigation and writing-review and editing. MA and

\section{REFERENCES}

Bernstein, C., Bernstein, H., Payne, C. M., Beard, S. E., and Schneider, J. (1999). Bile salt activation of stress response promoters in Escherichia coli. Curr. Microbiol. 39, 68-72. doi: 10.1007/s002849900420

Bo Andersen, J., Roldgaard, B. B., Christensen, B. B., and Licht, T. R. (2007). Oxygen restriction increases the infective potential of Listeria monocytogenes in vitro in Caco-2 cells and in vivo in guinea pigs. BMC Microbiol. 7:55. doi: 10.1186/1471-2180-7-55

Boonmee, A., Oliver, H. F., and Chaturongakul, S. (2019). Listeria monocytogenes sigma(A) is sufficient to survive gallbladder bile exposure. Front. Microbiol. 10:2070. doi: 10.3389/fmicb.2019.02070

Borezee, E., Pellegrini, E., and Berche, P. (2000). OppA of Listeria monocytogenes, an oligopeptide-binding protein required for bacterial growth at low temperature and involved in intracellular survival. Infect. Immun. 68, 70697077. doi: 10.1128/IAI.68.12.7069-7077.2000

Bowman, J. P., Hages, E., Nilsson, R. E., Kocharunchitt, C., and Ross, T. (2012). Investigation of the Listeria monocytogenes Scott A acid tolerance response and associated physiological and phenotypic features via whole proteome analysis. J. Proteome Res. 11, 2409-2426. doi: 10.1021/pr201137c

Burkholder, K. M., Kim, K. P., Mishra, K. K., Medina, S., Hahm, B. K., Kim, H., et al. (2009). Expression of LAP, a SecA2-dependent secretory protein, is induced under anaerobic environment. Microbes Infect. 11, 859-867. doi: 10.1016/j.micinf.2009.05.006

Chang, C., and Stewart, R. C. (1998). The two-component system. Regulation of diverse signaling pathways in prokaryotes and eukaryotes. Plant Physiol. 117, 723-731. doi: 10.1104/pp.117.3.723

Chatterjee, S. S., Hossain, H., Otten, S., Kuenne, C., Kuchmina, K., Machata, S., et al. (2006). Intracellular gene expression profile of Listeria monocytogenes. Infect. Immun. 74, 1323-1338. doi: 10.1128/IAI.74.2.1323-1338.2006

Cheng, C., Wang, X., Dong, Z., Shao, C., Yang, Y., Fang, W., et al. (2015). Aminopeptidase T of M29 family acts as a novel intracellular virulence factor for Listeria monocytogenes infection. Sci. Rep. 5:17370. doi: 10.1038/srep17370

Chourashi, R., Mondal, M., Sinha, R., Debnath, A., Das, S., Koley, H., et al. (2016). Role of a sensor histidine kinase ChiS of Vibrio cholerae in pathogenesis. Int. J. Med. Microbiol. 306, 657-665. doi: 10.1016/j.ijmm.2016. 09.003
GS: resources. DC: data curation and writing-original draft preparation. All authors have read and agreed to the published version of the manuscript.

\section{FUNDING}

This research was funded by the National Institutes of Health, Mississippi INBRE grant number P20GM103476 and MSUCOBRE grant number P20GM103646.

\section{ACKNOWLEDGMENTS}

We would like to extend our acknowledgment to Christopher Bryson and Trevor Perry for helping us with analyzing the data set.

\section{SUPPLEMENTARY MATERIAL}

The Supplementary Material for this article can be found online at: https://www.frontiersin.org/articles/10.3389/fmicb. 2021.754748/full\#supplementary-material

Coleman, R., Iqbal, S., Godfrey, P. P., and Billington, D. (1979). Membranes and bile formation. Composition of several mammalian biles and their membranedamaging properties. Biochem. J. 178, 201-208. doi: 10.1042/bj1780201

Conesa, A., Gotz, S., Garcia-Gomez, J. M., Terol, J., Talon, M., and Robles, M. (2005). Blast2GO: a universal tool for annotation, visualization and analysis in functional genomics research. Bioinformatics 21, 3674-3676. doi: 10.1093/ bioinformatics/bti610

Corbett, D., Wang, J., Schuler, S., Lopez-Castejon, G., Glenn, S., Brough, D., et al. (2012). Two zinc uptake systems contribute to the full virulence of Listeria monocytogenes during growth in vitro and in vivo. Infect. Immun. 80, 14-21. doi: 10.1128/IAI.05904-11

Cotter, P. D., Gahan, C. G., and Hill, C. (2001). A glutamate decarboxylase system protects Listeria monocytogenes in gastric fluid. Mol. Microbiol. 40, 465-475. doi: 10.1046/j.1365-2958.2001.02398.x

Cui, G., Wang, J., Qi, X., and Su, J. (2018). Transcription elongation factor GreA plays a key role in cellular invasion and virulence of Francisella tularensis subsp. novicida. Sci. Rep. 8:6895. doi: 10.1038/s41598-018-25271-5

Davis, M. J., Coote, P. J., and O'Byrne, C. P. (1996). Acid tolerance in Listeria monocytogenes: the adaptive acid tolerance response (ATR) and growth-phasedependent acid resistance. Microbiology 142(Pt 10), 2975-2982. doi: 10.1099/ 13500872-142-10-2975

Dons, L., Eriksson, E., Jin, Y., Rottenberg, M. E., Kristensson, K., Larsen, C. N., et al. (2004). Role of flagellin and the two-component CheA/CheY system of Listeria monocytogenes in host cell invasion and virulence. Infect. Immun. 72, 3237-3244. doi: 10.1128/IAI.72.6.3237-3244.2004

Dowd, G. C., Joyce, S. A., Hill, C., and Gahan, C. G. (2011). Investigation of the mechanisms by which Listeria monocytogenes grows in porcine gallbladder bile. Infect. Immun. 79, 369-379. doi: 10.1128/IAI.00330-10

Dramsi, S., Dehoux, P., Lebrun, M., Goossens, P. L., and Cossart, P. (1997). Identification of four new members of the internalin multigene family of Listeria monocytogenes EGD. Infect. Immun. 65, 1615-1625. doi: 10.1128/iai. 65.5.1615-1625.1997

Espey, M. G. (2013). Role of oxygen gradients in shaping redox relationships between the human intestine and its microbiota. Free Radic. Biol. Med. 55, 130-140. doi: 10.1016/j.freeradbiomed.2012.10.554

Garriga, X., Eliasson, R., Torrents, E., Jordan, A., Barbe, J., Gibert, I., et al. (1996). nrdD and nrdG genes are essential for strict anaerobic growth of Escherichia 
coli. Biochem. Biophys. Res. Commun. 229, 189-192. doi: 10.1006/bbrc.1996. 1778

Grove, A. (2013). MarR family transcription factors. Curr. Biol. 23, R142-R143. doi: 10.1016/j.cub.2013.01.013

Guariglia-Oropeza, V., Orsi, R. H., Guldimann, C., Wiedmann, M., and Boor, K. J. (2018). The Listeria monocytogenes bile stimulon under acidic conditions is characterized by strain-specific patterns and the upregulation of motility, cell wall modification functions, and the PrfA regulon. Front. Microbiol. 9:120. doi: $10.3389 /$ fmicb. 2018.00120

Hardy, J., Francis, K. P., DeBoer, M., Chu, P., Gibbs, K., and Contag, C. H. (2004). Extracellular replication of Listeria monocytogenes in the murine gall bladder. Science 303, 851-853. doi: 10.1126/science.1092712

Harris, J., Paul, O., Park, S. H., White, S. J., Budachetri, K., McClung, D. M., et al. (2019). Oxygen deprivation influences the survival of Listeria monocytogenes in gerbils. Transl. Anim. Sci. 3, 102-112. doi: 10.1093/tas/txy110

He, G., Shankar, R. A., Chzhan, M., Samouilov, A., Kuppusamy, P., and Zweier, J. L. (1999). Noninvasive measurement of anatomic structure and intraluminal oxygenation in the gastrointestinal tract of living mice with spatial and spectral EPR imaging. Proc. Natl. Acad. Sci. U.S.A. 96, 4586-4591. doi: 10.1073/pnas.96. 8.4586

Isabella, V. M., and Clark, V. L. (2011). Identification of a conserved protein involved in anaerobic unsaturated fatty acid synthesis in Neiserria gonorrhoeae: implications for facultative and obligate anaerobes that lack FabA. Mol. Microbiol. 82, 489-501. doi: 10.1111/j.1365-2958.2011.07826.x

Jydegaard-Axelsen, A. M., Hoiby, P. E., Holmstrom, K., Russell, N., and Knochel, S. (2004). CO2- and anaerobiosis-induced changes in physiology and gene expression of different Listeria monocytogenes strains. Appl. Environ. Microbiol. 70, 4111-4117. doi: 10.1128/AEM.70.7.4111-4117.2004

Karatzas, K. A., Wouters, J. A., Gahan, C. G., Hill, C., Abee, T., and Bennik, M. H. (2003). The CtsR regulator of Listeria monocytogenes contains a variant glycine repeat region that affects piezotolerance, stress resistance, motility and virulence. Mol. Microbiol. 49, 1227-1238. doi: 10.1046/j.1365-2958.2003.03636. $\mathrm{X}$

Kaspar, D., Auer, F., Schardt, J., Schindele, F., Ospina, A., Held, C., et al. (2014). Temperature- and nitrogen source-dependent regulation of GlnR target genes in Listeria monocytogenes. FEMS Microbiol. Lett. 355, 131-141. doi: 10.1111/ 1574-6968.12458

Kaval, K. G., Hahn, B., Tusamda, N., Albrecht, D., and Halbedel, S. (2015). The PadR-like transcriptional regulator LftR ensures efficient invasion of Listeria monocytogenes into human host cells. Front. Microbiol. 6:772. doi: 10.3389/ fmicb.2015.00772

Krell, T., Lacal, J., Busch, A., Silva-Jimenez, H., Guazzaroni, M. E., and Ramos, J. L. (2010). Bacterial sensor kinases: diversity in the recognition of environmental signals. Annu. Rev. Microbiol. 64, 539-559. doi: 10.1146/annurev.micro.112408. 134054

Kuenemann, M. A., Spears, P. A., Orndorff, P. E., and Fourches, D. (2018). In silico predicted glucose-1-phosphate uridylyltransferase (GalU) inhibitors block a key pathway required for Listeria virulence. Mol. Inform. 37:e1800004. doi: 10.1002/ minf.201800004

Linnan, M. J., Mascola, L., Lou, X. D., Goulet, V., May, S., Salminen, C., et al. (1988). Epidemic listeriosis associated with Mexican-style cheese. N. Engl. J. Med. 319, 823-828. doi: 10.1056/NEJM198809293191303

Liu, Y., and Ream, A. (2008). Gene expression profiling of Listeria monocytogenes strain F2365 during growth in ultrahigh-temperature-processed skim milk. Appl. Environ. Microbiol. 74, 6859-6866. doi: 10.1128/AEM.00356-08

Mariscotti, J. F., Quereda, J. J., Garcia-Del Portillo, F., and Pucciarelli, M. G. (2014). The Listeria monocytogenes LPXTG surface protein Lmo1413 is an invasin with capacity to bind mucin. Int. J. Med. Microbiol. 304, 393-404. doi: 10.1016/j.ijmm.2014.01.003

Monte, M. J., Marin, J. J., Antelo, A., and Vazquez-Tato, J. (2009). Bile acids: chemistry, physiology, and pathophysiology. World J. Gastroenterol. 15, 804816. doi: 10.3748/wjg.15.804

Nakano, M. M., Zhu, Y., Haga, K., Yoshikawa, H., Sonenshein, A. L., and Zuber, P. (1999). A mutation in the 3-phosphoglycerate kinase gene allows anaerobic growth of Bacillus subtilis in the absence of ResE kinase. J. Bacteriol. 181, 7087-7097. doi: 10.1128/JB.181.22.7087-7097.1999

Nelson, K. E., Fouts, D. E., Mongodin, E. F., Ravel, J., DeBoy, R. T., Kolonay, J. F., et al. (2004). Whole genome comparisons of serotype $4 \mathrm{~b}$ and $1 / 2 \mathrm{a}$ strains of the food-borne pathogen Listeria monocytogenes reveal new insights into the core genome components of this species. Nucleic Acids Res. 32, 2386-2395. doi: $10.1093 /$ nar/gkh562

Nevo, Y., and Nelson, N. (2006). The NRAMP family of metal-ion transporters. Biochim. Biophys. Acta 1763, 609-620. doi: 10.1016/j.bbamcr.2006.05.007

Niu, S., Luo, M., Tang, J., Zhou, H., Zhang, Y., Min, X., et al. (2013). Structural basis of the novel $S$. pneumoniae virulence factor, GHIP, a glycosyl hydrolase 25 participating in host-cell invasion. PLoS One 8:e68647. doi: 10.1371/journal. pone. 0068647

Ofer, A., Kreft, J., Logan, D. T., Cohen, G., Borovok, I., and Aharonowitz, Y. (2011). Implications of the inability of Listeria monocytogenes EGD-e to grow anaerobically due to a deletion in the class III NrdD ribonucleotide reductase for its use as a model laboratory strain. J. Bacteriol. 193, 2931-2940. doi: 10. 1128/JB.01405-10

O’Neil, H. S., and Marquis, H. (2006). Listeria monocytogenes flagella are used for motility, not as adhesins, to increase host cell invasion. Infect. Immun. 74, 6675-6681. doi: 10.1128/IAI.00886-06

Parsons, C., Lee, S., Jayeola, V., and Kathariou, S. (2017). Novel cadmium resistance determinant in Listeria monocytogenes. Appl. Environ. Microbiol. 83:e02580-16. doi: 10.1128/AEM.02580-16

Paruthiyil, S., Pinochet-Barros, A., Huang, X., and Helmann, J. D. (2020). Bacillus subtilis TerC family proteins help prevent manganese intoxication. J. Bacteriol. 202:e0624-19. doi: 10.1128/JB.00624-19

Paudyal, R., O’Byrne, C. P., and Karatzas, K. A. (2020). Amino acids other than glutamate affect the expression of the GAD system in Listeria monocytogenes enhancing acid resistance. Food Microbiol. 90:103481. doi: 10.1016/j.fm.2020. 103481

Payne, A., Schmidt, T. B., Nanduri, B., Pendarvis, K., Pittman, J. R., Thornton, J. A., et al. (2013). Proteomic analysis of the response of Listeria monocytogenes to bile salts under anaerobic conditions. J. Med. Microbiol. 62(Pt 1), 25-35. doi: 10.1099/jmm.0.049742-0

Prieto, A. I., Ramos-Morales, F., and Casadesus, J. (2004). Bile-induced DNA damage in Salmonella enterica. Genetics 168, 1787-1794. doi: 10.1534/genetics. 104.031062

Prieto, A. I., Ramos-Morales, F., and Casadesus, J. (2006). Repair of DNA damage induced by bile salts in Salmonella enterica. Genetics 174, 575-584. doi: 10.1534/ genetics.106.060889

Quillin, S. J., Schwartz, K. T., and Leber, J. H. (2011). The novel Listeria monocytogenes bile sensor BrtA controls expression of the cholic acid efflux pump MdrT. Mol. Microbiol. 81, 129-142. doi: 10.1111/j.1365-2958.2011. 07683.x

Scallan, E., Hoekstra, R. M., Angulo, F. J., Tauxe, R. V., Widdowson, M. A., Roy, S. L., et al. (2011). Foodborne illness acquired in the United States-major pathogens. Emerg. Infect. Dis 17, 7-15. doi: 10.3201/eid1701.P11101

Scortti, M., Monzo, H. J., Lacharme-Lora, L., Lewis, D. A., and Vazquez-Boland, J. A. (2007). The PrfA virulence regulon. Microbes Infect. 9, 1196-1207. doi: 10.1016/j.micinf.2007.05.007

Slamti, L., and Lereclus, D. (2019). The oligopeptide ABC-importers are essential communication channels in Gram-positive bacteria. Res. Microbiol. 170, 338 344. doi: 10.1016/j.resmic.2019.07.004

Sleator, R. D., and Hill, C. (2005). A novel role for the LisRK two-component regulatory system in listerial osmotolerance. Clin. Microbiol. Infect. 11, 599-601. doi: 10.1111/j.1469-0691.2005.01176.x

Stock, A. M., Robinson, V. L., and Goudreau, P. N. (2000). Two-component signal transduction. Annu. Rev. Biochem. 69, 183-215. doi: 10.1146/annurev.biochem. 69.1 .183

Supuran, C. T. (2016). Legionella pneumophila carbonic anhydrases: underexplored antibacterial drug targets. Pathogens 5:44. doi: 10.3390/pathogens5020044

Tessema, G. T., Moretro, T., Snipen, L., Heir, E., Holck, A., Naterstad, K., et al. (2012). Microarray-based transcriptome of Listeria monocytogenes adapted to sublethal concentrations of acetic acid, lactic acid, and hydrochloric acid. Can. J. Microbiol. 58, 1112-1123. doi: 10.1139/w2012-091

Thigpen, M. C., Whitney, C. G., Messonnier, N. E., Zell, E. R., Lynfield, R., Hadler, J. L., et al. (2011). Bacterial meningitis in the United States, 1998-2007. N. Engl. J. Med. 364, 2016-2025. doi: 10.1056/NEJMoa1005384

Torrents, E. (2014). Ribonucleotide reductases: essential enzymes for bacterial life. Front. Cell Infect. Microbiol. 4:52. doi: 10.3389/fcimb.2014. 00052 
Trapnell, C., Hendrickson, D. G., Sauvageau, M., Goff, L., Rinn, J. L., and Pachter, L. (2013). Differential analysis of gene regulation at transcript resolution with RNA-seq. Nat. Biotechnol. 31, 46-53. doi: 10.1038/nbt.2450

Trapnell, C., Pachter, L., and Salzberg, S. L. (2009). TopHat: discovering splice junctions with RNA-Seq. Bioinformatics 25, 1105-1111. doi: 10.1093/ bioinformatics/btp 120

Trapnell, C., Williams, B. A., Pertea, G., Mortazavi, A., Kwan, G., van Baren, M. J., et al. (2010). Transcript assembly and quantification by RNA-Seq reveals unannotated transcripts and isoform switching during cell differentiation. Nat. Biotechnol. 28, 511-515. doi: 10.1038/nbt.1621

Turner, A. G., Ong, C. L., Gillen, C. M., Davies, M. R., West, N. P., McEwan, A. G., et al. (2015). Manganese homeostasis in group A Streptococcus is critical for resistance to oxidative stress and virulence. mBio 6:e00278-15. doi: 10.1128/ mBio.00278-15

van der Veen, S., and Abee, T. (2011). Contribution of Listeria monocytogenes RecA to acid and bile survival and invasion of human intestinal Caco-2 cells. Int. J. Med. Microbiol. 301, 334-340. doi: 10.1016/j.ijmm.2010.11.006

Volkov, A., Liavonchanka, A., Kamneva, O., Fiedler, T., Goebel, C., Kreikemeyer, B., et al. (2010). Myosin cross-reactive antigen of Streptococcus pyogenes M49 encodes a fatty acid double bond hydratase that plays a role in oleic acid detoxification and bacterial virulence. J. Biol. Chem. 285, 10353-10361. doi: 10.1074/jbc.M109.081851

West, A. H., and Stock, A. M. (2001). Histidine kinases and response regulator proteins in two-component signaling systems. Trends Biochem. Sci. 26, 369376. doi: 10.1016/s0968-0004(01)01852-7

White, S. J., McClung, D. M., Wilson, J. G., Roberts, B. N., and Donaldson, J. R. (2015). Influence of $\mathrm{pH}$ on bile sensitivity amongst various strains of Listeria monocytogenes under aerobic and anaerobic conditions. J. Med. Microbiol. 64, 1287-1296. doi: 10.1099/jmm.0.000160
Wright, M. L., Pendarvis, K., Nanduri, B., Edelmann, M. J., Jenkins, H. N., Reddy, J. S., et al. (2016). The effect of oxygen on bile resistance in Listeria monocytogenes. J. Proteomics Bioinform. 9, 107-119. doi: 10.4172/jpb.1000396

Wu, H., Qiao, S., Li, D., Guo, L., Zhu, M., and Ma, L. Z. (2019). Crystal structure of the glycoside hydrolase PssZ from Listeria monocytogenes. Acta Crystallogr. F Struct. Biol. Commun. 75(Pt 7), 501-506. doi: 10.1107/S2053230X1900 8100

Zheng, L., Kelly, C. J., and Colgan, S. P. (2015). Physiologic hypoxia and oxygen homeostasis in the healthy intestine. A review in the theme: cellular responses to hypoxia. Am. J. Physiol. Cell. Physiol. 309, C350-C360. doi: 10.1152/ajpcell. 00191.2015

Conflict of Interest: The authors declare that the research was conducted in the absence of any commercial or financial relationships that could be construed as a potential conflict of interest.

Publisher's Note: All claims expressed in this article are solely those of the authors and do not necessarily represent those of their affiliated organizations, or those of the publisher, the editors and the reviewers. Any product that may be evaluated in this article, or claim that may be made by its manufacturer, is not guaranteed or endorsed by the publisher.

Copyright (c) 2021 Chakravarty, Sahukhal, Arick, Davis and Donaldson. This is an open-access article distributed under the terms of the Creative Commons Attribution License (CC BY). The use, distribution or reproduction in other forums is permitted, provided the original author(s) and the copyright owner(s) are credited and that the original publication in this journal is cited, in accordance with accepted academic practice. No use, distribution or reproduction is permitted which does not comply with these terms. 